\title{
Estimating the price of default risk
}

\author{
Gregory R. Duffee \\ Federal Reserve Board \\ Mail Stop 91 \\ Washington, DC 20551 \\ 202-452-3055 \\ gduffee@frb.gov \\ First version September 1995 \\ Current version July 1996
}

\begin{abstract}
A firm's instantaneous probability of default is modeled as a square-root diffusion process. The parameters of these processes are estimated for 188 firms, using both the time series and cross-sectional (term structure) properties of the individual firms' bond prices. Although the estimated models are moderately successful at bond pricing, there is strong evidence of misspecification. The results indicate that single factor models of instantaneous default risk face a significant challenge in matching certain key features of actual corporate bond yield spreads. In particular, such models have difficulty generating both relatively flat yield spreads when firms have low credit risk and steeper yield spreads when firms have higher credit risk.
\end{abstract}

JEL Classifications: G12, G13

Key words: term structure, credit risk, credit ratings, corporate bonds, credit derivatives

I thank Torben Andersen, Mark Fisher, Dilip Madan, Ken Singleton, and Chunsheng Zhou for helpful conversations, and seminar participants at an NBER Derivatives Project meeting for helpful comments. The analysis and conclusions of this paper are those of the author and do not indicate concurrence by other members of the research staff, by the Board of Governors, or by the Federal Reserve Banks. 


\section{Introduction}

The risk of default affects virtually every financial contract. Therefore the pricing of default risk has received much attention; both from traders, who have a strong interest in accurately pricing transactions, and financial economists, who have much to learn from the way such risks are priced in markets. The standard theoretical paradigm for modeling credit risks is the contingent claims approach pioneered by Black and Scholes. Much of the literature follows Merton (1974) by explicitly linking the risk of a firm's default to the variability in the firm's asset value. Although this line of research has proven very useful in addressing the qualitatively important aspects of pricing credit risks, it has been less successful in practical applications. ${ }^{1}$ The lack of success owes to the difficulty of modeling realistic boundary conditions. These boundaries include both the conditions under which default occurs, and in the event of default, the division of the value of the firm among claimants. Firms' capital structures are typically quite complex and priority rules are often violated.

In response to these difficulties, an alternative modeling approach has been pursued in a number of recent papers, including Madan and Unal (1994), Duffie and Singleton (1995a, 1995b), and Jarrow and Turnbull (1995). ${ }^{2}$ At each instant there is some probability that a firm defaults on its obligations. Both this probability and the recovery rate in the event of default may vary stochastically through time. The stochastic processes determine the price of credit risk. Although these processes are not formally linked to the firm's asset value, there is presumably some underlying relation, thus Duffie and Singleton describe this alternative approach as a reduced form model.

This class of models is much more tractable mathematically than Merton-type models, raising hopes that it will be useful in practical applications. However, empirical implementation of this type of model is in its infancy. The few analyses that have been done to date fit such models to aggregate yield indexes, hence the ability of these models to price accurately the credit risks associated with particular instruments is unknown.

This paper is an effort to determine, on a broad scale, whether one such model can describe successfully individual corporate bond prices. The data consist of month-end observations on noncallable corporate bonds from January 1985 through December 1994; in total, over 40,000 bond-price observations across 188 firms. The vast majority of the bonds are rated investment grade.

I follow Chen and Scott (1993) and use maximum likelihood to estimate a two-factor, square-root diffusion model of default-free interest rates. The model is extended to corporate bonds by assuming that the instantaneous probability that a given firm defaults on its

1 One illustration of this lack of success is that very few papers have even attempted to price particular instruments. The standard reference is Jones, Mason, and Rosenfeld (1984), who find that, even for firms with very simple capital structures, a Merton-type model is unable to price investment-grade corporate bonds better than a naive model that assumes no risk of default.

${ }^{2}$ Researchers also continue to extend Merton-style models to address these problems. Recent examples are Longstaff and Schwartz (1995) and Zhou (1996). 
obligated bond payments follows a square-root diffusion process. To simplify the estimation procedure, I assume that each firm's instantaneous default probability process is independent of default-free interest rates.

The goal of this exercise is to determine which features of the data are well-described by this model, and which features are inconsistent with the model. In this vein, there are a number of issues to consider. How well does this single-factor process capture the crosssectional and time-series patterns in corporate bond yields? Is it appropriate to model firms' default probabilities as independent of default-free rates? I also consider the ability of the model to price instruments other than corporate bonds; in particular, credit derivatives with payoffs tied to multiple defaults on corporate bonds.

On average, the model fits corporate bond prices reasonably well. For the typical firm, the root mean squared error in yields is in the neighborhood of 18 basis points. However, the model fails in a number of ways. Some of these failures can be tied to the square-root specification of volatility, but others appear to be more generally applicable to single-factor descriptions of the evolution of default probabilities over time. The most basic failure is the inability of the model to simultaneously fit both the level and the slope of the term structure of investment grade bond yield spreads (over Treasuries). For the typical firm and maturities examined in this paper, the observed term structure of yield spreads is positively sloped, and the slope is positively related to the level of spreads. For example, when the level of a typical investment-grade firm's term structure of spreads is low, it is also close to horizontal. When the level rises, so does the slope. (Earlier research has observed the same pattern in the term structures of aggregate yield spreads on investment-grade bonds.)

This pattern implies that under the equivalent martingale measure, the drift in instantaneous default risk must be positively related to its level. The problem is that the size of the positive relation that is needed to explain the variation in the slope of the term structure is inconsistent with the very flat term structures that are observed when the instantaneous default probability is low. Roughly speaking, even if a firm currently has a very low instantaneous default risk, the possibility (under the equivalent martingale measure) of a future explosive increase in this risk is too large to be consistent with a very flat term structure of yield spreads.

Single factor models also are of limited use in pricing derivative instruments that have payoffs tied to the joint default behavior of firms with closely tied prospects (say, S\&Ls in Texas during the 1980s). The difficulty is that these models are unable to generate default correlations across firms that are much larger than zero.

The next section discusses some of the previous empirical work in this area. It is followed by a brief description of the model and the estimation procedure. The fourth and fifth sections report the results of estimating the default-free interest rate process and firms' default processes, respectively. The sixth section looks at the relation between credit ratings and default risk and the seventh section looks at credit derivative pricing. The eighth section concludes the paper.

\section{Prior empirical evidence}

Academic research into credit risk pricing, including the present paper, relies almost 
exclusively on the contingent-claims framework. It is worth noting that the assumptions underlying this framework are probably not satisfied. Although credit risk has existed ever since financial contracts were traded, in many respects credit risk is the new frontier of asset pricing on Wall Street. Because the stochastic behavior of credit risk is not well-understood by market participants, identifying potential arbitrage opportunities is difficult. In addition, markets for credit risk are typically illiquid and asymmetric information problems abound.

In order to understand the effects that credit risks have on asset prices, it makes sense to focus on those markets where credit risk is important. By this metric, it is natural to look at corporate bond prices. The pricing of credit risk is much more important for corporate bonds than for interest rate swaps, because default risk should have a very small effect on swap prices (Sorensen and Bollier 1994, Duffie and Huang 1996). Moreover, the market for seasoned corporate bonds is relatively more liquid than the (practically nonexistent) market for seasoned swaps.

Madan and Unal (1994) examine another financial instrument for which credit risk is important: Certificates of deposit issued by roughly 300 thrift institutions over January 1987 to December 1991. They used a model of instantaneous default risk to relate the time variation in average thrift $C D$ rates to variations in average thrift stock prices, core deposit ratios, and returns to an index of low-grade bonds.

Grinblatt (1995) explores the relation between mid-market interest-rate swap spreads and LIBOR, although he argues that this relation is driven by a liquidity yield to Treasury securities instead of default risk. He estimates two different single-factor forms of this spread (square-root and Gaussian). The use of yield indexes, instead of firm-specific yields, is justified in Grinblatt's work because of his maintained assumption that default risk is essentially irrelevant in the determination of swap spreads.

Duffie and Singleton (1995b) also analyze mid-market swap quotes, modeling swap yields with a two-factor square-root process. Because they are unwilling to assume that swap quotes are unrelated to default risk, their use of mid-market yields on newly-issued swaps is explicitly justified by assuming that all swap counterparties maintain a credit rating of A until the swap matures or default occurs. Although clearly at odds with reality, any errors induced by this assumption are small because swap yields are not very responsive to variations in default risk.

Nielsen and Ronn (1996) assume that instantaneous corporate yield spreads over defaultfree yields follow a geometric random walk, while default-free interest rates are described by a one-factor model with deterministic time-varying coefficients. They fit their model to both corporate bond yield indexes and swap spreads. Their estimation procedure uses only cross-sectional data, not time-series data, thus they cannot identify the true (i.e., physical) processes, and their estimated parameters change from day to day. The use of refreshed yield indexes is more difficult to justify when analyzing corporate bond yield spreads than when analyzing swap yields. Duffee (1996) finds that empirically, refreshed corporate bond yield indexes underrespond to actual variations in credit quality. This result is not surprising, considering that corporate bond yields are quite sensitive to variations in credit quality, but refreshed yield indexes hold constant one measure of credit quality (credit ratings). 


\section{The model and the estimation technique}

The use of multiple independent factors to model term structures of interest rates is common because such models are very tractable. A textbook treatment is in Duffie (1996). Madan and Unal (1994), Duffie and Singleton (1995a), and Lando (1994) describe how to extend such models to the pricing of instruments subject to default risk. The model below is straightforward, therefore certain details are relegated to Appendix 1.

3a. A model of default risk

I start by modeling default-free interest rates. The instantaneous nominal default-free interest rate is denoted $r_{t}$. Denote the time- $t$ price of a default-free bond that pays off a dollar at time $T$ as $P(t, T, 0)$. (The third argument is the bond's coupon payment, which is zero.) The price of this bond is given by the expectation, under the equivalent martingale measure, of the cumulative discount rate between $t$ and $T$ :

$$
P(t, T, 0)=E_{t}^{Q}\left\{\exp \left[-\int_{t}^{T} r_{u} d u\right]\right\}
$$

I assume that $r_{t}$ equals the sum of two factors, $y_{1, t}$ and $y_{2, t}$, that follow independent square-root stochastic processes.

$$
\begin{gathered}
r_{t}=y_{1, t}+y_{2, t} ; \\
d y_{i, t}=\kappa_{i}\left(\theta_{i}-y_{i, t}\right) d t+\sigma_{i} \sqrt{y_{i, t}} d Z_{i, t}, \quad d Z_{1, t}, d Z_{2, t} \text { independent. }
\end{gathered}
$$

Under the equivalent martingale measure, these processes can be represented as

$$
d y_{i, t}=\left(\kappa_{i} \theta_{i}-\left(\kappa_{i}+\lambda_{i}\right) y_{i, t}\right) d t+\sigma_{i} \sqrt{y_{i, t}} d \hat{Z}_{i, t}, \quad d \hat{Z}_{1, t}, d \hat{Z}_{2, t} \text { independent. }
$$

The stochastic processes in (3) imply a closed-form solution for zero-coupon bond prices. The solution is a simple extension of Cox, Ingersoll, and Ross's (1985) single-factor bond price equation. The solution is well-known, and is given in Appendix 1.

Default is modeled as an unpredictable jump in a Poisson process. The intensity of the process for firm $j$ at time $t$ is denoted $h_{j, t}$. In other words, the probability, under the equivalent martingale measure, that firm $j$ defaults during the time $(t, t+d t)$, conditional on the firm not defaulting prior to $t$, is $h_{j, t} d t$. Throughout this paper I use the terms "instantaneous probability of default" and "instantaneous default risk" interchangeably; they both refer to $h_{j, t}$. It should be emphasized that $h_{j, t}$ will not equal the true instantaneous probability of default as long as the market price of risk associated with the Poisson process is nonzero.

Now consider the price of a zero-coupon bond, issued by firm $j$, that pays a dollar at time $T$ unless firm $j$ defaults at or before $T$. In the event of default, the bond pays off nothing. Denote the price of this bond as $V_{j}(t, T, 0,0)$. (The third argument is the 
bond's coupon; the fourth is the recovery value in the event of default.) The price of this bond is given by the expectation, under the equivalent martingale measure, of an adjusted cumulative discount rate between $t$ and $T$. This adjusted discount rate is $r_{t}+h_{j, t}$. Therefore the bond price is

$$
V_{j}(t, T, 0,0)=E_{t}^{Q}\left\{\exp \left[-\int_{t}^{T}\left(r_{u}+h_{j, u}\right) d u\right]\right\}
$$

I model the intensity $h_{j, t}$ as a single-factor square-root process, as shown in (5):

$$
d h_{j, t}=\kappa_{j}\left(\theta_{j}-h_{j, t}\right) d t+\sigma_{j} \sqrt{h_{j, t}} d Z_{j, t}
$$

Under the equivalent martingale measure, this process can be written as

$$
d h_{j, t}=\left(\kappa_{j} \theta_{j}-\left(\kappa_{j}+\lambda_{j}\right) h_{j, t}\right) d t+\sigma_{j} \sqrt{h_{j, t}} d \hat{Z}_{j, t}
$$

The Brownian motion driving $h_{j, t}$ is assumed to be independent of the Brownian motions driving the default-free interest rate factors $y_{1, t}$ and $y_{2, t}$. Therefore the appropriate discount rate used for pricing the corporate bond is the sum of three independent square-root processes, for which a closed-form solution is easily calculated and is in Appendix 1.

Recall that (4) is the price of a zero-coupon corporate bond that pays nothing in the event of default. However, modeling payments to bondholders in the event of default is of great practical importance because the amounts recovered are large. Moody's finds that on average, senior unsecured bondholders receive approximately 44 percent of par in the event of default. Consider a senior unsecured zero-coupon bond issued by firm $j$ that promises to pay, at time $T$, one dollar. This paper follows Jarrow, Lando, and Turnbull (1994), among others, in assuming that the bond pays a fixed dollar value $\delta$ at time $T$ in the event of default at or prior to $T$.

The assumption of a constant recovery rate is obviously greatly at odds with reality. However, it should be thought of as an approximation to a model in which there is very little information revealed about a bond's recovery value until the issuer is close to default. Das and Tufano (1995) argue that recovery rates vary systematically with default-free interest rates, but their evidence is too preliminary to justify a more complicated analysis here.

The price of a zero-coupon bond with recovery rate $\delta$ is denoted $V_{j}(t, T, 0, \delta)$. The absence of arbitrage requires that after default, the price of this bond equals the price of a default-free zero coupon bond paying $\delta$ and maturing at time $T$. In addition, no arbitrage requires that, prior to default,

$$
V_{j}(t, T, 0, \delta)=\delta P(t, T, 0)+(1-\delta) V_{j}(t, T, 0,0)
$$

Therefore zero-coupon bonds with recovery value in the event of default can be easily priced in terms of default-free and default-risky, no-recovery zero-coupon bonds. The empirical work that follows uses bonds that pay coupons semiannually. The prices of such bonds are simply the sum of the prices of the individual cash flows associated with the bonds. 


\section{3b. Estimation methodology}

There are a number of methods that can be used to estimate this model using both the cross-sectional and time series properties of bond yields. I adopt the method used by Chen and Scott (1993) in their analysis of Treasury yields and Duffie and Singleton (1995b) in their analysis of swap yields. They assume that, with an $n$-factor term structure model, the prices of exactly $n$ bonds are measured without error at each time period. ${ }^{3}$ Given the model parameters, the bond prices can be inverted to identify each period's state variables. With some structure placed on the measurement error of other bonds' prices, the conditional log densities of each period's entire term structure of bond prices can be calculated. The model is estimated by finding the set of parameters that maximizes the sum of conditional log likelihoods.

Although this description of measurement error is ad hoc (and almost certainly false), it is extremely convenient. In addition, by altering the points on the corporate bond yield curve that are assumed measured without error, this approach will prove useful in investigating possible model misspecification.

I use month-end prices of Treasury bonds and corporate bonds issued by 188 firms to estimate, using maximum likelihood, the parameters of (2), (3), (5), and (6). ${ }^{4}$ The parameters of (5) and (6) are firm-specific, i.e. they are not restricted to be constant across firms.

Firm $j$ 's bond prices depend on the processes for $y_{1, t}$ and $y_{2, t}$ as well as the process for $h_{j, t}$. Thus it would be more efficient to estimate the default-free interest rate and default probability processes jointly instead of separately. Unfortunately, it is infeasible to jointly estimate the default-free processes and all 188 default probability processes. An alternative is, for each firm, to jointly estimate the default-free processes and the default-risky process for that firm. However, this alternative has the unsatisfying feature that there are as many different estimated default-free processes as there are firms. I therefore estimate the defaultfree processes once, using only Treasury bond data. I then use the resulting parameter estimates and implied observations of the state variables $y_{1, t}$ and $y_{2, t}$ to separately estimate the parameters of each firm's instantaneous default process. (In other words, 188 different maximum likelihood optimization problems were solved, one for each firm.) Details of the estimation procedure are in Appendix 2.

\section{Default-free parameter estimation}

At each month-end from January 1985 through December 1994, prices of seven different Treasury noncallable coupon bonds are observed. (The data are from CRSP.) The shortest-

${ }^{3}$ Chen and Scott actually assume that the sum of $\log$ bond prices is observed without error.

4 The use of Treasury bonds to estimate the default-free term structure is not innocuous. Grinblatt (1995) argues that Treasuries provide a liquidity yield, so that the spread of corporate bonds over Treasury bonds reflects both credit risk and this 'convenience' yield. In addition, income from Treasury bonds is not taxable at the state level, unlike income from corporate bonds. 
maturity bond in every month has slightly less than six months to maturity (i.e., it is a zero-coupon bond.) The other bonds have maturities of approximately one, three, five, seven, ten and thirty years. The actual maturities vary somewhat over the period, as do the coupons.

I assume that the one-year and ten-year bonds are measured without error. This choice is a pragmatic one. The maturities of the corporate bonds examined in this paper are concentrated in the one to ten year range, hence to accurately extract default probabilities, it is more important to accurately fit the default-free term structure in this range than in other ranges (say, at the very short or long ends). All other log bond prices are observed with error. The measurement error for bond $i$ at time $t$ has variance $S_{i}^{2}$, which is constant over time. For simplicity, measurement errors are assumed to be independent across $t$ and $i$.

Estimation results are displayed in Table 1. Standard errors are computed from the outer product of the first derivatives. The results are similar to those of Chen and Scott. The first factor is closely related to the (negative of) the spread between long and short bond yields. This relation is illustrated in the top panel of Fig. 1, which displays both the fitted values of $y_{1, t}$ and the spread between the three-month Treasury bill yield and the thirty-year constant-maturity bond yield constructed by the Treasury. (Note that neither of these yields were used in the estimation.) The correlation between the fitted values and the short-long spread is 0.966 and the correlation between first differences of the two series is 0.711 . This factor exhibits statistically and economically significant mean reversion; its half-life is slightly less than 11 months.

The second factor is closely related to long bond yields, as illustrated in bottom panel of Fig. 1. The fitted values of $y_{2, t}$ move almost in lockstep with the Treasury's 30 -year bond yield. (The correlation of first differences is 0.952.) We cannot reject the hypothesis that this factor follows a martingale (i.e., $\kappa_{2}=0$ ).

The standard errors on the parameters used for bond pricing, $\kappa_{i} \theta_{i}, \kappa_{i}+\lambda_{i}$, and $\sigma_{i}^{2}$, are all very small. Because this model assumes that two points on the yield curve are observed without error, these small standard errors imply that the exact shape of the yield curve is known to great precision. In other words, there is very little uncertainty about the true value of $y_{1, t}, y_{2, t}$, or their sum $r_{t}$. The mean asymptotic standard error for $y_{1, t}$ is 14.5 basis points (b.p.), while the corresponding mean for $y_{2, t}$ is 14.1 b.p. ${ }^{5}$ These errors are strongly negatively correlated, thus the mean asymptotic standard error for $r_{t}$ is only $1.3 \mathrm{~b}$.p.

This two-factor model cannot accurately price all Treasury bonds. As Table 1 indicates, the root mean squared errors in the yields range from an average of $27 \mathrm{~b}$.p. for the six month bond to 11 b.p. for the 30 year bond. The relatively large error in the six-month bond yield is a consequence of modeling errors in log prices instead of yields. For a given error in a log bond price, the corresponding error in yield is much larger for short-maturity bonds than for long-maturity bonds.

${ }^{5}$ Denote the gradient of the implied state variable $y_{i, t}$ with respect to the parameters as $\nabla y_{i, t}$ and the variance-covariance matrix of the estimated parameters as $\Sigma$. The asymptotic standard error for $y_{i, t}$ is $\left[\left(\nabla y_{i, t}\right)^{\prime} \Sigma \nabla y_{i, t}\right]^{1 / 2}$. 

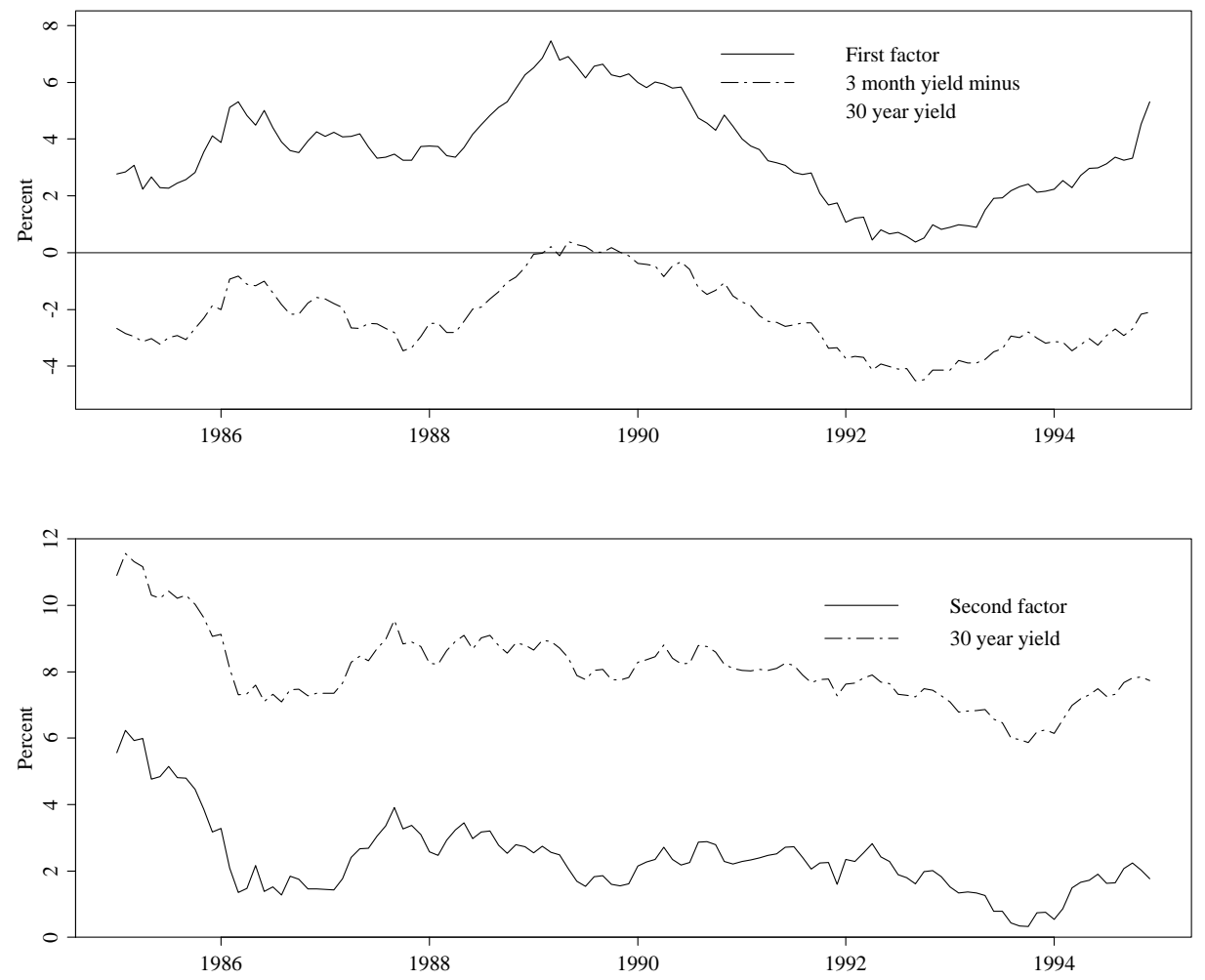

Figure 1. The estimated factors for a two factor square-root model of Treasury bond yields

The instantaneous default-free interest rate is assumed to equal the sum of two factors that follow square-root diffusion processes. The model is estimated with maximum likelihood using a panel of monthly Treasury bond data from 1985:1 through 1994:12. Also displayed are the Treasury's constant-maturity 30-year bond yield and the spread between the three-month Treasury bill yield and the 30 -year bond yield.

Careful consideration of the estimated default-free rate process is beyond the scope of this paper. However, there is evidence of misspecification. The model assumes that the process for $y_{1, t}$ is independent of the process for $y_{2, t}$, but the fitted values of $y_{1, t}$ and $y_{2, t}$ are negatively correlated. Denote the fitted values by $\hat{y}_{1, t}$ and $\hat{y}_{1, t}$. The correlation between $\hat{y}_{1, t}-\hat{y}_{1, t-1}$ and $\hat{y}_{1, t}-\hat{y}_{2, t-1}$ is -0.445 . Perhaps a more relevant correlation is that between innovations to the two processes. Estimated innovations can be constructed by first defining

$$
\begin{gathered}
E_{t-1}^{*}\left(y_{i, t}\right)=E\left(y_{i, t} \mid y_{i, t-1}=\hat{y}_{i, t-1}, \kappa_{i}=\hat{\kappa}_{i}, \theta=\hat{\theta}_{i}, \sigma_{i}^{2}={\widehat{\sigma^{2}}}_{i}\right), \\
\operatorname{Var}_{t-1}^{*}\left(y_{i, t}\right)=\operatorname{Var}\left(y_{i, t} \mid y_{i, t-1}=\hat{y}_{i, t-1}, \kappa_{i}=\hat{\kappa}_{i}, \theta=\hat{\theta}_{i}, \sigma_{i}^{2}={\widehat{\sigma^{2}}}_{i}\right) .
\end{gathered}
$$


Thus in (8), the estimated parameters are treated as the true parameters in forming $E_{t-1}^{*}\left(y_{i, t}\right)$ and $\operatorname{Var}_{t-1}^{*}\left(y_{i, t}\right)$. Then an estimate of the period- $t$ innovation in $y_{i, t}$ is $\left[\hat{y}_{i, t}-\right.$

$\left.E_{t-1}^{*}\left(y_{i, t}\right)\right] / \sqrt{\operatorname{Var}_{t-1}^{*}\left(y_{i, t}\right)}$. The resulting correlation between the estimated innovations in $y_{1, t}$ and $y_{2, t}$ is -0.383 .

\section{Default risk parameter estimation}

This section forms the heart of the paper. It is divided into seven subsections. The first describes the data. The second overviews the estimation technique and results. The third and fourth discuss, in detail, the results based on a particular rule used to choose those corporate bond prices that are assumed to be measured without error. The fifth discusses alternative results, based on a different rule used to choose perfectly-observed bond prices. The sixth compares these sets of results and discusses which is more relevant for bond-pricing purposes. The seventh subsection examines the time series properties of firms' default risks, including specification tests for two key assumptions of the model: The independence between default intensities and default-free interest rates and the square-root formulation of volatility.

\subsection{Data description}

Corporate bond data are taken from the Fixed Income Database from the University of Wisconsin-Milwaukee, which consists of month-end data on the bonds that make up the Lehman Brothers Bond Indexes. This dataset, which is discussed in more detail in Warga (1991) and Duffee (1996), covers primarily investment-grade firms. I consider only noncallable, nonputable, senior unsecured straight bonds with semiannual coupons, no variation in promised coupon payments over time, no sinking fund provisions, original maturities of under 35 years, and with at least one year remaining to maturity. Bond price observations that are calculated using a matrix are dropped. Therefore all prices are indicative bid prices quoted by traders. Relatively few noncallable bonds were issued prior to 1985, hence I examine only the period beginning January 1985 and ending December 1994.

I start with a sample of 188 firms, where a firm is defined as any entity with a distinct six-digit CUSIP. ${ }^{6}$ Firm $j$ has a month $t$ "observation" if the firm has at least two bonds with valid prices in month $t$ and at least one bond with a valid price in month $t-1$. If these conditions are met, then the conditional density of the observation can be calculated. Each of the 188 firms has at least 36 monthly observations. (Therefore each of these firms has at least 37 months of bond price data.) Firms sometimes issue a number of bonds with very similar maturity dates. Yields on such bonds are typically very closely linked. Therefore to reduce the size of my maximization problem, in these cases I use a selection of bonds. ${ }^{7}$

${ }^{6}$ Parents and their subsidiaries may have different six-digit CUSIPS. For example, my sample includes Ford Motors, Ford Motor Credit, and Ford Capital B.V. as separate firms.

7 For a given firm and month, I select the bond with remaining maturity closest to one year, then the bond with remaining maturity closest to two years (which may be the same bond as that previously selected), and so on up to thirty years. For example, if a firm has 
The median number of observations for each firm is 52 ; the mean is 60.25 , for a total of 11,327 observations of monthly transitions across all firms. Five firms have observations throughout the period, or a total of 119 observations. Recall that each observation consists of at least two month $t$ bond prices. Approximately 35 percent of the 11,327 observations have only two month- $t$ bond prices. Twenty percent of the observations have three month- $t$ bond prices, while fifteen percent have four bond prices. The maximum number of bonds for any firm and any month is 25 .

The model assumes that for each firm, a single corporate bond price is observed without error in every month. The chosen bond price must be consistent with the default-free interest rate process estimated above. Of the more than 44,000 corporate bond prices used to estimate default-risky processes, 36 are higher than the implied price of a default-free bond with the same maturity and coupon. Therefore these bond prices must be observed with error to rule out arbitrage opportunities.

\subsection{Details of the estimation procedure}

For each firm $j$, I estimate the instantaneous default risk process twice. The first estimation assumes that the bond observed without error in month $t$ is the bond with the longest remaining maturity in that month. This choice is based on evidence that more recently issued bonds have more accurate quoted prices, probably because they are much more actively traded than are seasoned bonds (Warga 1991). Therefore, for any two corporate bonds with the same original maturity, the bond with the longer remaining maturity is more likely to have an accurate price. To examine the robustness of the results, the second estimation assumes that the bond closest to five years to maturity is observed without error.

All other $\log$ bond prices are observed with iid, normally distributed measurement error with variance $S_{j}^{2}$. Therefore for a given firm, all measurement errors are assumed to the same variance. This common variance is unfortunate, because the maturities of these bonds vary, sometimes substantially, across time. However, because both the number of bonds and maturities vary over time, there is no other clear way to model these variances. (For example, I might assume that there are two measurement error variances; one for short maturities and one for long maturities. But this would effectively require that I exclude from my estimation all of firm $j$ 's monthly observations that consist of only two bond prices, because for these observations a conditional likelihood cannot be computed. As mentioned above, this is 35 percent of the data.)

I assume that the recovery in the event of default is 44 percent of the value of an otherwise equivalent default-free instrument. Other details of the estimation procedure are given in Appendix 2. One important detail deserves mention here. I do not assume stationarity of the instantaneous default risk process. Therefore I do not use the unconditional distribution of the initial observation in the maximum-likelihood procedure, and hence instead of requiring both $\kappa_{j}>0$ and $\theta_{j} \geq 0$, I only require $\kappa_{j} \theta_{j} \geq 0$.

bonds with remaining maturities of $1.9,2.2,2.5$, and 3.4 years, I drop the bonds with 2.2 and 2.5 years to maturity. The bond with 1.9 years to maturity is included because it is the bond closest to both one and two years to maturity; the bond with 3.4 years to maturity is included because it is the bond closest to a three-year maturity. 
The estimates of instantaneous default probabilities for most of the 188 firms are reasonable. However, results for a few firms are implausible. For example, when the bond closest to five years to maturity is assumed measured without error, three of the firms have implied instantaneous default probabilities that at times exceed 6.5 (the equivalent of a $650 \%$ instantaneous discount rate for default). These firms' data have a common feature: Each monthly observation contains exactly two bonds. By assumption, one of these bond prices is observed without error, thus the parameter estimates that maximize the likelihood function need only fit a single other point on the corporate bond term structure. For these three firms, this maximization resulted in parameter estimates that were wildly unrealistic at other points on the term structure.

This discussion suggests that reliable results for a given firm are more likely if, for at least one monthly observation, there are data for more than two points on the firm's corporate term structure. This criterion is met for 160 of the 188 firms in my sample. I henceforth restrict my attention to the parameter estimates for these 160 firms. An alternative is to drop only the three firms with very high implied default probabilities, but I cannot be confident that inaccurate estimation will always show up in the form of high estimates of instantaneous default probabilities. The 160 remaining firms are listed in Appendix 3.

In the discussion that follows, I use hats $(\hat{x})$ to refer to estimated values. Table 2 summarizes the results for the 160 remaining firms. The table reports the median and interquartile range of each estimated parameter (there are 160 estimates of each parameter, one for each firm).

It also reports the median and interquartile range of three firm-specific values: Firm $j$ 's mean $\hat{h}_{j, t}$, the square root of the mean of the squared differences between the actual and fitted yields on firm $j$ 's bonds (RMSE), and firm $j$ 's mean estimated probability, under the equivalent martingale measure, that it defaults within five years. ${ }^{8}$ Panel A reports the results based on no measurement error in the longest bond's price, while Panel B reports the results based on no measurement error in the price of the bond closest to five years to maturity. I now discuss in detail the results in Panel A.

\subsection{Results assuming no measurement error in the long bond}

The summary of firms' $\hat{\kappa}_{j}$ 's in Panel A of Table 2 indicates that for most firms, their instantaneous default probability is a martingale. Therefore for these firms, $\theta_{j}$ is an irrelevant parameter. This panel also indicates that $\hat{\lambda}_{j}$ is typically negative. Of the 160 firms, 139 have negative estimates of $\lambda_{j}$. These negative values imply that investors require compensation for variations in default risk. Put another way, assets that pay off when firms' default probabilities are high are highly valued by investors.

8 The probability, formed at time $t$, that firm $j$ defaults within five years from time $t$ is given by $1-E^{Q}\left[\exp \left(-\int_{t}^{t+5} h_{j, u} d u\right)\right]$. I use the estimated parameters for firm $j$ 's instantaneous default probability process to evaluate this expectation. I define firm $j$ 's mean estimated five-year probability of default as the mean of this estimated expectation, over all $t$. 
Panel A also documents that default probabilities under the equivalent martingale measure are substantially higher than those implied by the historical incidence of default. The median firm's mean $\hat{h}_{j, t}$ is 1.3 percent. The median firm's mean five-year estimated cumulative default probability is 8.0 percent. Default probabilities based on observations of actual defaults are much smaller. The bulk of the firms in my sample are rated either A or Baa by Moody's. Fons, Carty, and Kaufman (1994) reports the historical probability of a Baa-rated firm defaulting within five years is only two percent, while the historical probability for an A-rated firm is less than one percent.

Within the framework of models of instantaneous default probabilities, there are two possible ways to reconcile high equivalent martingale default probabilities with low actual default probabilities. The first is with a negative price of risk of innovations in default probabilities. (In the specific model examined in this paper, $\lambda_{j}<0$.) In other words, the market prices corporate bonds as if instantaneous default probabilities are expected to rise faster than the physical measure implies. Indeed, in Panel A, we see $\hat{\lambda}_{j}<0$, but for these parameter estimates, the effect is modest. The median firm's mean estimated fiveyear cumulative default probability under the physical measure is 5.9 percent. (This is not reported in Table 2.) Although lower than the median of 8.0 percent under the equivalent martingale measure, this value is still much larger than the historical default rate.

The other way to reconcile these high probabilities with historical evidence is to recognize that $h_{j, t}$ is the instantaneous probability of default under the equivalent martingale measure, not necessarily under the physical measure. Evidently, instantaneous default probabilities under the physical measure are smaller than $h_{j, t}$ : Assets that pay off in states of the world in which the event of default occurs are highly valued. This is unfortunate for those who wish to estimate pricing models for corporate bonds. It says that empirically-observed default rates, such as those reported by Moody's, cannot be applied directly in models used for pricing. ${ }^{9}$ We return to this issue in Section 7.

How volatile is the risk of default? Volatility depends on both $\sigma_{j}^{2}$ and $h_{j, t}$. When both values are at their median values in Panel $\mathrm{A}$, the instantaneous annualized standard deviation of $h_{j, t}$ is 77.7 basis points, or roughly 22 basis points per month. Whether this is large or small depends on your metric. One way to think about this value is to compare it to the volatility of the instantaneous default-free rate implied by the model of Section 4 . If both $y_{1, t}$ and $y_{2, t}$ are at their mean fitted values over 1985 through 1994, the instantaneous annualized standard deviation of $r_{t}$ implied by the variance estimates in Table 1 is 1.896 percent, or 55 basis points per month. Therefore for the typical firm, the standard deviation of the instantaneous default probability is about two-fifths that of the instantaneous defaultfree rate.

\subsection{Cross-sectional pricing errors}

On average, the model fits corporate bond prices reasonably well. The median estimate

${ }^{9}$ Lando (1994) describes how empirical default rates can be incorporated into no-arbitrage models of corporate bond prices under the assumption that the empirical instantaneous risk of default equals the equivalent martingale instantaneous risk of default. 


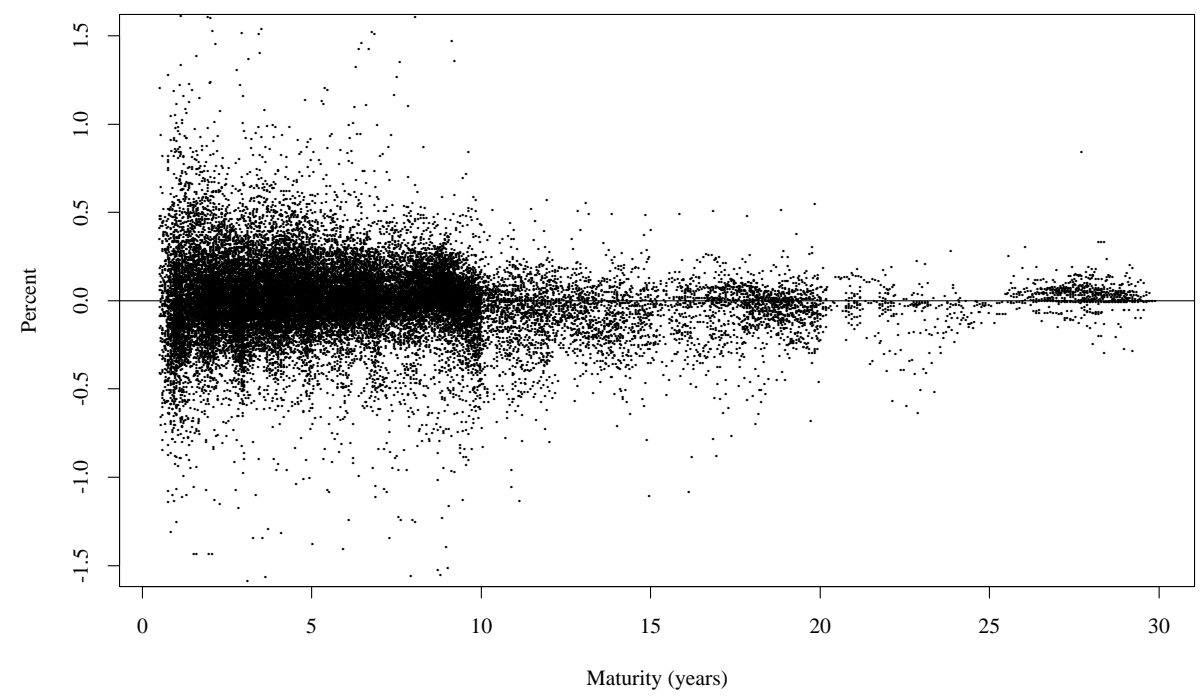

Figure 2. Errors in fitting bond yields

This figure displays yield errors (actual less fitted) produced by maximum likelihood estimation of one factor square-root diffusion models of firms' instantaneous default probabilities. The estimation assumes that in each month, the price of each firm's longest-maturity bond is observed without error. All other log bond prices are observed with normally distributed measurement error.

of $S_{j}^{2}$ implies a standard deviation of log bond prices of 73 cents per $\$ 100$. It is often easier to think of errors in yield space instead of log price space. Panel A reports that the median root mean squared yield error is slightly over 18 basis points. Fig. 2 displays the actual yields less the fitted yields for all firms and bonds. ${ }^{10}$ Because the longest available bond's price is assumed to be measured without error, we expect that the largest yield errors are concentrated at the short maturities. In addition, as mentioned earlier, bonds with short remaining maturities are also more subject to price errors induced by nontrading.

However, this model has a serious problem in fitting certain features of corporate bond yields. The first sign of the problem is the striking estimates of the parameters associated with the equivalent martingale measure. Most of the estimates of $\kappa_{j} \theta_{j}$ are zero, which is the boundary of the parameter space. In fact, 96 of 160 estimates are indistinguishable from zero. ${ }^{11}$ In addition, $\hat{\kappa}_{j}+\hat{\lambda}_{j}$ is negative for most firms (133 of 160). Therefore under the equivalent martingale measure, instantaneous default risk is explosive for most firms, in the sense that higher levels of risk correspond to more rapid growth in risk.

These parameter estimates reflect some well-known features of corporate bond prices. Earlier research has shown that on average across investment-grade bonds, the term structure of yield spreads is upward sloped. ${ }^{12}$ This positive slope is stronger for lower-rated bonds

\footnotetext{
10 A few extreme outliers are not shown.

11 Because of this fact, typical methods of statistical inference are invalid. For this reason, I do not report standard errors for the parameter estimates.

12 The focus here is on investment-grade bonds because the dataset has little information on speculative-grade bonds. The slopes of term structures of yield spreads for speculative-
} 
than higher-rated bonds. For example, Fons (1994) finds that yield spreads for Aaa-rated bonds are essentially flat across maturities, while yield spreads for Baa-rated bonds increase about two basis points for each additional year to maturity. Similar evidence is reported in Duffee (1996) and in Litterman and Iben (1991; see their Fig. 3). This pattern is the source of the negative estimates of $\kappa_{j}+\lambda_{j}$. When instantaneous default risk is low (say, when a bond is rated Aaa), it must also be expected, under the equivalent martingale measure, to remain low, otherwise flat yield spreads could not be generated. When instantaneous default risk is high, must be expected to increase further in order to generate steep yield spreads. Therefore under the equivalent martingale measure, instantaneous default risk is not only nonstationary, it is explosive.

When $\kappa_{j}+\lambda_{j}$ is negative, term structures of yield spreads implied by this model must be rising (at least at first) even if the firm's instantaneous default risk is very low. In addition, a positive value of $\kappa_{j} \theta_{j}$ imparts a positive slope to the term structure of yield spreads at all levels of default risk. But because actual term structures of yield spreads are very flat when they are very low, slopes implied by the model may be greater than those in the data even if $\kappa_{j} \theta_{j}=0$. This is the basic problem the model has in fitting the cross-sectional data: The model cannot simultaneously match low, flat term structures and high, steeper term structures.

To graphically illustrate this problem, I report some detailed results for bonds issued by Citicorp. In late 1990, Citicorp experienced substantial financial difficulties. These difficulties were reflected in large yield spreads on their bonds in November 1990, as shown in the top panel of Fig 3. In this figure, the solid squares represent actual Treasury coupon bond yields and the solid line connects the Treasury yields implied by the two-factor model of default-free yields estimated in Section 4. Actual yields on Citicorp's bonds, shown with solid triangles, range from 150 basis points over Treasuries at the one-year horizon to 400 basis points over Treasuries at the nine-year horizon. Over time, the difficulties subsided, and by June 1994, yield spreads on Citicorp's bonds had dramatically fallen from their earlier levels, as shown in the bottom panel of Fig. 3.

The single-factor square-root process for Citicorp's instantaneous default risk was estimated over August 1987 through December 1994. The estimates for the equivalent martingale measure are $\hat{\kappa}_{j} \hat{\theta}_{j}=0, \hat{\kappa}_{j}+\hat{\lambda}_{j}=-0.240$, and $\widehat{\sigma^{2}}{ }_{j}=0.00944$. The yields implied by this model for Citicorp's bonds are shown with hollow triangles in Fig. 3. It is clear from Fig. 3 that the estimated parameters produce term structures of yield spreads that are too flat when yield spreads are high and too steep when yield spreads are low. The only way to lower the slope of the June 1994 fitted term structure is to increase the value of $\kappa_{j}+\lambda_{j}$, but this would also lower the slope of the November 1994 fitted term structure. Although this example is extreme, chosen to illustrate the point, the fact that $\kappa_{j} \theta_{j}$ is estimated to be zero for 60 percent of the firms examined in this paper is strong evidence that this single-factor process is fundamentally misspecified.

grade bonds are examined by Sarig and Warga (1989), Fons (1994), and Helwege and Turner (1995). On balance, the evidence concerning the slope of the typical speculative-grade term structure is mixed. 
November 30, 1990

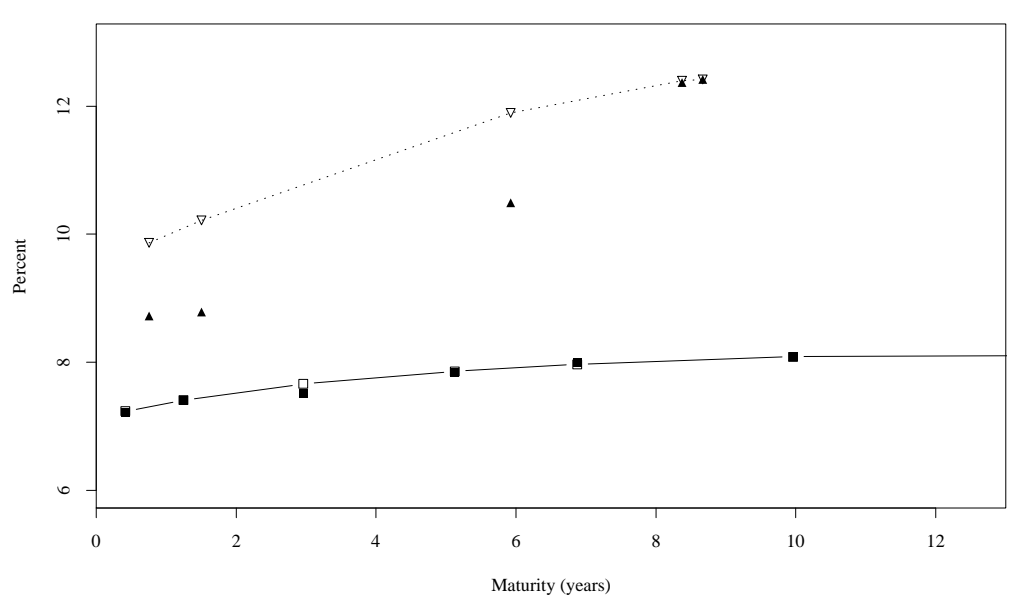

June 30, 1994

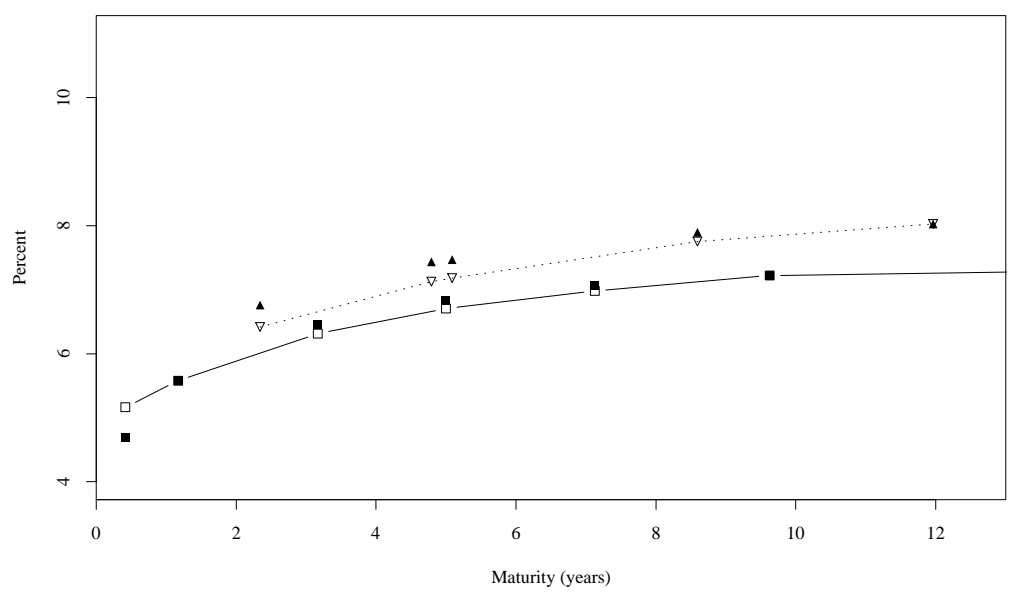

Figure 3. Actual and fitted yield curves for Citicorp

Solid squares are actual Treasury yields. Hollow squares are fitted Treasury yields; they are connected by the solid lines. Solid triangles are actual yields on Citibank bonds. Hollow triangles are fitted yields; they are connected by the dotted lines. The corporate bonds yields are estimated under the assumption that the price of the longest bond is observed without error.

A graphical summary of the extent of this misspecification for all 160 firms is in Fig. 4. For each firm $j$, the monthly estimates of $h_{j, t}$ were sorted into quartiles. For all $t$ in the lowest quartile, the errors in bond yields (actual less fitted) are plotted in the top panel of Fig. 4. For all $t$ in the highest quartile, the errors in bond yields are plotted in the bottom panel of Fig. 4. Therefore the top panel displays the errors made by the model when firms' levels of default risk are substantially lower than average and the bottom panel displays the errors when firms' levels of default risk are substantially higher than average. 

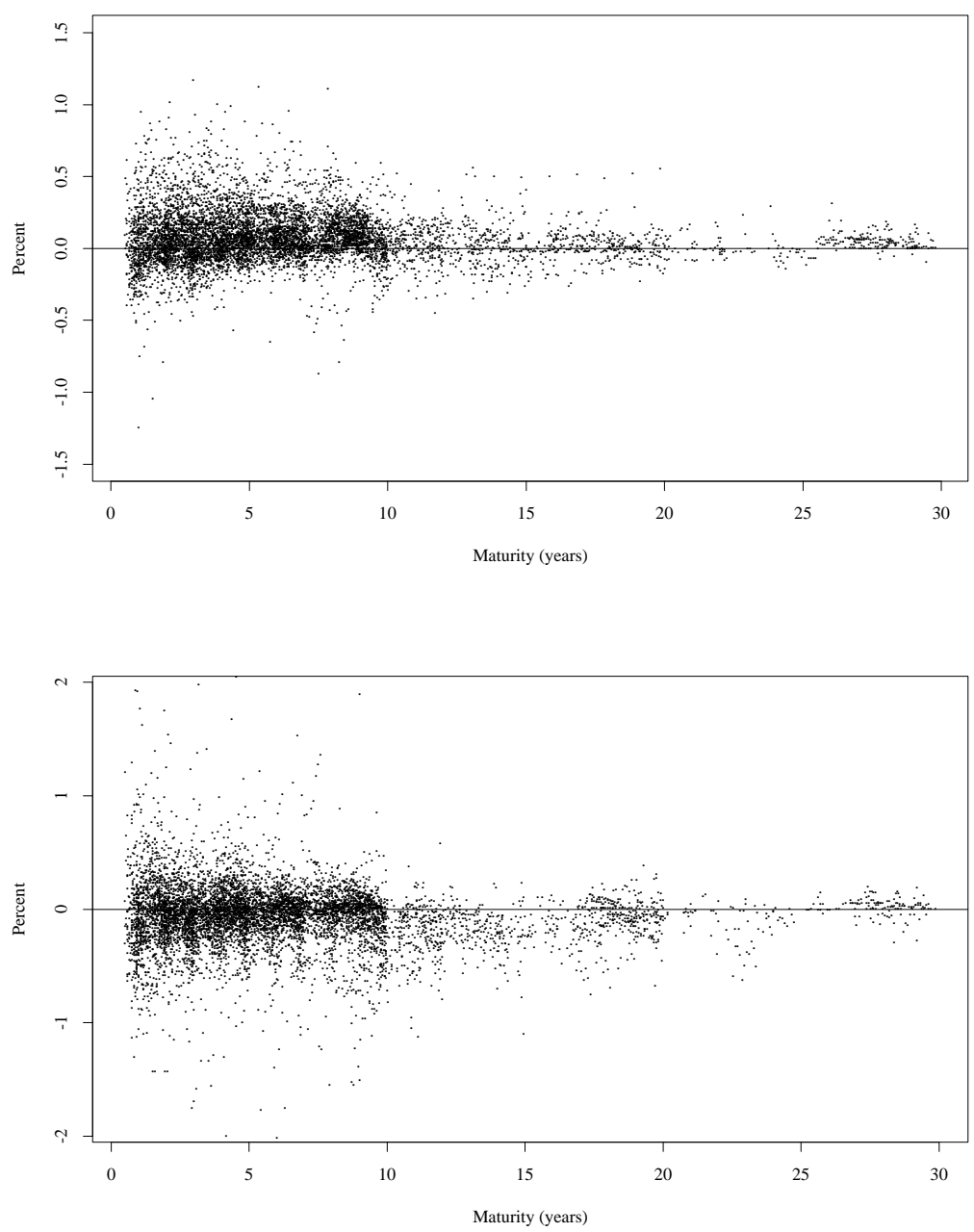

Figure 4. Errors in fitting bond yields

This figure displays yield errors (actual less fitted) produced by maximum likelihood estimation of one factor square-root diffusion models of firms' instantaneous default risks. The estimation assumes that in each month, the price of each firm's longest-maturity bond is observed without error. All other log bond prices are observed with normally distributed measurement error. The top panel displays errors for the lowest quartile of estimated default risks and the bottom panel displays errors for the highest quartile of estimated default risks.

The average error in the top panel of Fig. 4 is positive (7.1 basis points), while the average error in the bottom panel is negative ( -6.2 basis points). Recall that by construction, the fitted and actual yield spread curves always meet at the long end. Therefore in the top panel, the average fitted yield spread curve lies below the corresponding actual yield spread curve everywhere but at the long end; i.e., the fitted yield spread curve is steeper. In the bottom panel, the signs are reversed, hence the average fitted yield spread curve is flatter than the actual yield spread curve. 


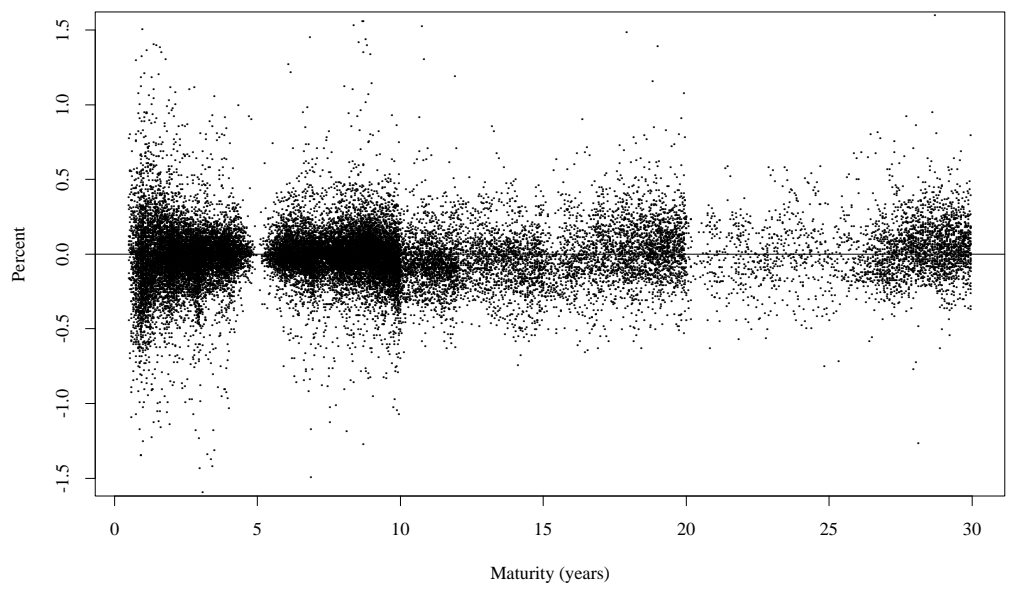

Figure 5. Errors in fitting bond yields

This figure displays yield errors (actual less fitted) produced by maximum likelihood estimation of one factor square-root diffusion models of firms' instantaneous default risks. The estimation assumes that in each month, the price of each firm's bond closest to five years to maturity is observed without error. All other log bond prices are observed with normally distributed measurement error.

\subsection{Results assuming no measurement error in the five-year bond}

As in Panel A of Table 2, the parameter estimates associated with the equivalent martingale measure in Panel B of Table 2 are striking, but they are striking only in the sense that they are dramatically different from those in Panel A. The estimate of $\kappa_{j} \theta_{j}$ is positive for most firms (all but 13 firms have positive estimates). Also in contrast to Panel A, instantaneous default probabilities are not explosive for most firms: For 90 of the firms, $\hat{\kappa}_{j}+\hat{\lambda}_{j}$ is positive.

Another difference between Panels A and B is in the models' implied volatilities of instantaneous default risk. The median estimate of $\sigma_{j}^{2}$ in Panel B is more than twice as large as the corresponding median estimate in Panel A. When $\sigma_{j}^{2}$ and $h_{j, t}$ are at their median values in Panel B, the instantaneous annualized standard deviation of $h_{j, t}$ is 34 basis points a month, versus 22 basis points a month for Panel A. This difference is examined in more detail in the next section.

In some other ways, the results in Panel B are similar to those in Panel A. Equivalent martingale default probabilities are higher in Panel B (both instantaneous probabilities and five-year probabilities), but only marginally so. Fig. 5 displays the actual yields less the fitted yields for all firms and bonds. Note that price errors disappear at the five-year horizon.

Because the estimated parameters are on the boundary of the parameter space for only a few firms, we can construct standard errors for most of these estimates. I use the outer product of first derivatives of the log-likelihood function and do not adjust them for the fact that the default-free parameters are estimated instead of known with certainty. Summary statistics for the standard errors are not reported in Table 2, but are available on request.

Here I summarize a couple of features of these standard errors. In general, the median standard errors for these parameters are somewhat larger than the standard errors for the 
corresponding parameters of the default-free processes. As with the standard errors for the default-free processes, the standard errors for the parameters that are identified under the equivalent martingale measure are estimated much more precisely than are other parameters. For example, the median standard error for $\kappa_{j}+\lambda_{j}$ is 0.023 , versus median standard errors for $\kappa_{j}$ and $\lambda_{j}$ of 0.41 and 0.40 respectively. The hypothesis that instantaneous default risk is a martingale $\left(\kappa_{j}=0\right)$ cannot be rejected for any firm. By contrast, the corresponding hypothesis under the equivalent martingale measure $\left(\kappa_{j}+\lambda_{j}=0\right)$ can be rejected at the $5 \%$ level for most firms, with the rejections roughly equally split between positive and negative values of $\kappa_{j}+\lambda_{j}$.

\subsection{Interpreting the differences between the two sets of results}

What accounts for the differences between Panels A and B? In particular, why do the estimates in Panel B not imply the explosive default risk under the equivalent martingale measure that is necessary to capture the steeper yield curves for higher credit risks?

The basic reason appears to be the assumption that log prices, instead of yields, are measured with error. An examination of Figs. 2 and 5 indicates that the long bond yield errors associated with fitting the term structure with five-year bond prices are somewhat smaller than the five-year bond yield errors associated with fitting the term structure with long bond prices. However, yield errors made at long horizons correspond to much larger errors in $\log$ prices than do yield errors made at short horizons. Therefore estimates of variances of log price errors are much larger in Panel B than in Panel A. Panel B's median estimate of $S_{j}^{2}$ is nearly 1.7 times the corresponding estimate in Panel A.

This larger variance of $\log$ price implies that maximum-likelihood estimation does not penalize as heavily parameter estimates that poorly match the varying slopes of corporate bond term structures: The resulting standardized errors are small because $\widehat{S^{2}}{ }_{j}$ is large. Therefore the maximum-likelihood estimations used to construct Panel B place relatively less weight on matching the cross-sectional properties of the data than do the maximumlikelihood estimations used to construct Panel A. Relatively more weight is placed on the time-series properties of the data. We return to this issue in the next subsection.

Although less weight is placed on the cross-sectional properties in Panel B, the median root mean squared errors in fitted yields are nonetheless smaller in Panel B than in Panel A. This is a consequence of forcing the fitted term structure through (roughly) the middle of the cross-sectional data, rather than forcing it through an endpoint of the cross-sectional data in Panel A.

This analysis suggests that modeling errors in yields instead of log prices may be fruitful. However, measurement error, as opposed to misspecification error, is probably better modeled in log prices. Corporate bonds are quoted, traded, and reported in prices, not yields. Therefore errors in quotes (say, transcription errors or bid/ask errors) are more naturally modeled in prices. Misspecification errors may be more appropriately modeled in yields, but if we take model misspecification seriously, it makes more sense to abandon the single factor square-root model in favor of a more flexible alternative.

An additional problem with the instantaneous probabilities of default estimated in Panel B is that they are based on bond prices that are both noisy and stale. To discuss 
this issue, we first need a little notation. Denote the estimates of instantaneous default probabilities constructed with the assumption of no measurement error at the long end as $\hat{h}_{j, t}^{\text {long }}$. Denote the estimates constructed with the assumption of no measurement error at the five-year horizon as $\hat{h}_{j, t}^{5 y r}$. To investigate the extent of noise and staleness in these two time series of estimated default probabilities, I regress changes in one measure on current and two lagged changes in the other. The median parameter estimates from firm-by-firm OLS regression of $\Delta \hat{h}_{j, t}^{5 y r}$ on lags zero through two of $\Delta \hat{h}_{j, t}^{\text {long }}$ are

$$
\Delta \hat{h}_{j, t}^{5 y r}=0.766 \Delta \hat{h}_{j, t}^{\text {long }}+0.099 \Delta \hat{h}_{j, t-1}^{\text {long }}+0.068 \Delta \hat{h}_{j, t-1}^{\text {long }}+\eta_{j, t}^{5 y r},
$$

The median parameter estimates from the firm-by-firm OLS regression of the reversed equation are

$$
\Delta \hat{h}_{j, t}^{\text {long }}=0.366 \Delta \hat{h}_{j, t}^{5 y r}+0.005 \Delta \hat{h}_{j, t-1}^{5 y r}-0.023 \Delta \hat{h}_{j, t-1}^{5 y r}+\eta_{j, t}^{\text {long }} .
$$

According to the parameter estimates in (9), a change in $\hat{h}_{j, t}^{\text {long }}$ is eventually almost completely matched one-for-one by a change in $\hat{h}_{j, t}^{5 y r}$ (the sum of the parameter estimates is $0.933)$, but much of the change in $\hat{h}_{j, t}^{5 y r}$ lags the change in $\hat{h}_{j, t}^{\text {long }}$. By contrast, (10) indicates that less than half of a given change in $\hat{h}_{j, t}^{5 y r}$ is matched by a change $\hat{h}_{j, t}^{\text {long }}$, and there is no lag in the response of $\hat{h}_{j, t}^{\text {long }}$. Therefore $\hat{h}_{j, t}^{5 y r}$ is both noisy and stale relative to $\hat{h}_{j, t}^{\text {long }}$.

\subsection{Time series properties of firms' default risk}

I now investigate how well the estimated parameters capture the time series behavior of default risk. Because the estimates of default risk produced by assuming no measurement error at the five-year horizon are both noisier and less fresh than are the estimates produced by assuming no measurement error at the long horizon, I focus exclusively on the latter estimates here. ${ }^{13}$

If the single factor square-root process is correctly specified, its parameters $\kappa, \theta$, and $\sigma^{2}$ summarize the time series properties of the process. Ball and Torous (1996) note that for such processes, the parameters are more precisely estimated if both the cross-sectional and time series properties of the term structure are used to estimate them. The primary reason for the greater precision is that $\kappa \theta$ is estimated very precisely in the cross section, so the information in the time series does not have to determine both $\kappa$ and $\theta$. (The cross section also contains information about $\sigma^{2}$ because Jensen's Inequality affects the slope of the term structure, but there is little difficulty in estimating $\sigma^{2}$ from the time series alone.)

Here, however, there is evidence of cross-sectional misspecification for many firms. Therefore the information in firm $j$ 's cross section concerning $\kappa_{j} \theta_{j}$ may be inconsistent with the actual time series properties of $\kappa_{j}$ and $\theta_{j}$. In particular, the restriction $\kappa_{j} \theta_{j}=0$ imposes a very strong requirement on the behavior of instantaneous default probabilities under the true, or physical measure. Either instantaneous default probabilities are a martingale or the long-run instantaneous default probability is zero. For most of these firms, the

13 Results for $\hat{h}_{j, t}^{5 y r}$ are available on request. 
restriction $\kappa_{j} \theta_{j}=0$ is met with $\hat{\kappa}_{j}=0$. I now investigate whether the time series properties of $\hat{h}_{j, t}$ are consistent with the martingale hypothesis. In other words, is $k_{j}=0$ a reasonable description of the time series behavior of firms' estimated instantaneous default risks?

Table 3 reports augmented Dickey-Fuller (ADF) tests (two lags) of nonstationarity for each firm's time series of $k_{j}$.

$$
\Delta \hat{h}_{j, t}=b_{0}+b_{1} \hat{h}_{j, t-1}+b_{2} \Delta \hat{h}_{j, t-1}+b_{3} \Delta \hat{h}_{j, t-2}+e_{j, t}
$$

Separate OLS regressions are estimated for each firm. (Results of estimating (11) with WLS, where the variance of $e_{j, t}$ is proportional to $\hat{h}_{j, t-1}$, are very similar to those reported in Table 3.) Medians and interquartile ranges are reported for each parameter and $t$-statistic. Based on the results in Table 3, there is only weak evidence of mean reversion. The $5 \%$ critical values for $b_{1}$ lie outside of the interquartile range. ${ }^{14}$

Only 30 of the 160 firms have test statistics that reject nonstationarity. Moreover, these statistical rejections of nonstationarity overstate the case for stationarity. Because instantaneous default probabilities are estimated, they are noisy measures of true instantaneous default probabilities. Therefore the ADF tests will overreject nonstationarity (Schwert 1989).

There is no compelling evidence in Table 3 that the maximum likelihood procedure produced poor estimates of $\kappa_{j}$. A more sophisticated analysis makes use of estimated normalized innovations to firms' instantaneous default risks. Define the estimated innovation $\epsilon_{j, t}$ as $\left[\hat{h}_{j, t}-E_{t-1}^{*}\left(h_{j, t}\right)\right] / \sqrt{\operatorname{Var}_{t-1}^{*}\left(h_{j, t}\right)}$, where the definitions of $E_{t-1}^{*}()$ and $\operatorname{Var}_{t-1}^{*}()$ are analogous to those in (8). If the model of instantaneous default risk is correctly specified, prior values of $\epsilon_{j, t}$ should not help forecast $\epsilon_{j, t}$.

I fit $\epsilon_{j, t}$ to an $\operatorname{AR}(3)$. Note that under the null hypothesis, the estimated coefficients are equal across all firms, as is the variance of the regression residual. Therefore I can estimate the $\operatorname{AR}(3)$ equation jointly across all $j$ :

$$
\begin{aligned}
& \epsilon_{j, t}=b_{0}+\sum_{i=1}^{3} b_{i} \epsilon_{j, t-i}+\eta_{j, t}, \\
& E\left(\eta_{j, t}\right)=0, E\left(\eta_{j, t}^{2}\right)=V \\
& E\left(\eta_{i, t} \eta_{j, t}\right)=\rho V, i \neq j, E\left(\eta_{i, t} \eta_{j, t-m}\right)=0, m \neq 0, \forall i, j .
\end{aligned}
$$

Under the null hypothesis that the model of instantaneous default risk is correctly specified, the AR coefficients should equal zero and the variance $V$ should equal one. Although the null hypothesis also specifies that the distribution of $\eta_{j, t}$ is a noncentral chi-square, for robustness I estimate (12) with quasi-maximum likelihood (QML). In other words, I assume that the errors $\eta_{j, t}$ are normally distributed with variance-covariance matrix described as in (12) and choose the parameter estimates to maximize the likelihood function. The standard

\footnotetext{
14 Five percent (one-tailed) critical values for the test that $b_{1}=0$ are $-3.00,-2.93$ and
} -2.89 for 25,50 , and 100 observations respectively. 
errors are then adjusted to account for nonnormality of the errors. In (12), note that the coefficients are not indexed by $j$; the estimated parameters are assumed to be equal across all $j$.

The results of QML estimation of (12) are reported as Regression [1] in Table 4. Specification error is evident. The normalized shock $\eta_{j, t}$ exhibits mean reversion, indicating that estimated values of $\kappa_{j}$ do not adequately capture the extent of mean reversion in $\hat{h}_{j, t}$. The point estimates indicate that 18 percent of a given shock is reversed within three months.

Of independent interest is the cross-correlation of innovations in firms' instantaneous default probabilities. The point estimate of $\rho$ is 0.24 , and as the $t$-statistic indicates, it is estimated very precisely. In other words, variations in firms' default probabilities have common components, but these common components are not very large compared to idiosyncratic components. This result is not altered by sorting firms by their senior unsecured credit ratings. In results that are available on request, QML estimation of (12) broken down by major credit rating (Aaa, Aa, etc.) produces similar estimates of $\rho$.

The other regressions reported in Table 4 examine the relation between default-free interest rates and estimated instantaneous default probabilities. This paper uses a closed form solution for zero-coupon corporate bond prices that relies on assumption that $h_{j, t}$ is independent of the components of the default-free interest rate, $y_{1, t}$ and $y_{2, t}$. Here I investigate the appropriateness of that assumption. As discussed in section $5, y_{1, t}$ is very closely related to the slope of the Treasury yield curve, as measured by the difference between the 30-year constant maturity yield and the three-month bill yield. The other factor $y_{2, t}$ is very closely related to the 30-year constant maturity yield. Therefore to avoid a generated regressor problem, I use changes in these observed term structure characteristics instead of changes in the fitted values of $y_{1, t}$ and $y_{2, t}$ to determine whether estimated innovations to instantaneous default probabilities are related to default-free interest rates.

First, I regress $\epsilon_{j, t}$ on the contemporaneous change in the 30-year Treasury yield, as well as three lagged changes in this Treasury yield. This yield is measured in percent per year. I jointly estimate (13) across all 160 firms using QML.

$$
\begin{aligned}
& \epsilon_{j, t}=b_{0}+\sum_{i=0}^{3} b_{i+1} \Delta Y_{30 y r, t-i}+\eta_{j, t}, \\
& E\left(\eta_{j, t}\right)=0, E\left(\eta_{j, t}^{2}\right)=V, \\
& E\left(\eta_{i, t} \eta_{j, t}\right)=\rho V, i \neq j, E\left(\eta_{i, t} \eta_{j, t-m}\right)=0, m \neq 0, \forall i, j .
\end{aligned}
$$

The results are reported as Regression [2] in Table 4. The point estimates imply that a decline in the Treasury yield corresponds to a contemporaneous increase in instantaneous default risk. This increase is essentially completely reversed during the next two to three months. A $\chi^{2}(1)$ test cannot reject the hypothesis the sum of the four coefficients equals zero. (The test statistic is 0.07 , with a $p$-value of 0.791 .)

This pattern of parameter estimates is suggestive of stale corporate bond prices, not a true nonzero correlation between the Treasury yield and default probabilities. Consider, for example, a decrease in the level of Treasury yields. If reported corporate bond yields do 
not immediately respond to this increase owing to stale prices, corporate yield spreads will spuriously rise. Over time, as reported corporate bond yields adjust, they will match the decrease in Treasury yields, causing yield spreads to return to their prior levels.

Regression [3] in Table 4 reports the results of estimating (12) with changes in the longshort Treasury yield spread on the right-hand-side instead of changes in the long Treasury yield. These results indicate no significant relation between the slope of the Treasury yield and instantaneous default probabilities.

These results support the idea that models of corporate bond pricing do not need to incorporate correlations between default-free rates and instantaneous default probabilities. This is extraordinarily convenient from a modeling perspective; see, for example, Lando (1994). It is worth noting that these results differ from the negative correlations between default-free interest rates and bond yield spreads found by Longstaff and Schwartz (1995) and Duffee (1996). However, neither of these earlier papers embedded their empirical work in a no-arbitrage model of default risk.

The final time series property of instantaneous default risk that I investigate is the specification of volatility. I ask two questions. First, does the square-root specification capture the true relation between $h_{j, t}$ and innovations in $h_{j, t}$ ? Second, are there persistent variations in volatility (ARCH effects) that are not accounted for by variations in the level of $h_{j, t}$ ? I estimate (14) jointly across all firms with QML:

$$
\begin{aligned}
& \epsilon_{j, t}^{2}=b_{0}+\sum_{i=1}^{3} b_{i} \epsilon_{j, t-i}^{2}+b_{4} \hat{h}_{j, t-1}+\eta_{j, t}, \\
& E\left(\eta_{j, t}\right)=0, E\left(\eta_{j, t}^{2}\right)=V, \\
& E\left(\eta_{i, t} \eta_{j, t}\right)=\rho V, i \neq j, E\left(\eta_{i, t} \eta_{j, t-m}\right)=0, m \neq 0, \forall i, j .
\end{aligned}
$$

In (14), the volatility of $\epsilon_{j, t}$ is measured with squared values. Davidian and Carroll (1987) conclude that when distributions are characterized by fat tails, it is often more efficient to estimate volatility functions using absolute values of residuals instead of squares. Therefore I also estimate (14) with $\left|\epsilon_{j, t}\right|$ in place of $\epsilon_{j, t}^{2}$. The results for both parameterizations are displayed in Table 5 .

Both sets of results show that there are ARCH effects in $\epsilon_{j, t}$. The evidence for $\mathrm{ARCH}$ effects is stronger when volatility is measured with absolute shocks. When volatility is measured with squared shocks, there is weak evidence that volatility is positively associated with the prior value of $\hat{h}_{j, t}$. This evidence is much stronger when volatility is measured with absolute shocks. Based on this evidence, the assumption that the volatility of instantaneous default risk rises with the square-root of this risk appears to underestimate the true sensitivity of the volatility of risk with respect to the level of risk.

\section{Credit ratings and default risk}

Consider a typical firm with A-rated senior unsecured debt in month $t$. What does the credit rating tell us about the firm's default risk in month $t$ ? What does the credit rating 
tell us about the future behavior of the firm's default risk? These questions are addressed in Table 6. Credit ratings are from Moody's unless a bond had no Moody's credit rating in the dataset. In this case an S\&P rating was used. For the purposes of this discussion, a firm's credit rating is defined as the rating on the firm's senior unsecured bonds.

Panel A of the table reports median estimates of the parameters of firms' default probability processes, sorted by the firms' "initial" credit ratings, which is defined as a firm's credit rating as of the first month of data used to estimate the instantaneous default process for the firm. The results show that the typical stochastic processes for Aa-rated, A-rated, and Baa-rated firms are very similar (except to the extent that credit quality shows up in the level of instantaneous default risk $h_{j, t}$ ). Across these credit ratings, there is no obvious pattern between credit quality and any of the parameters, except a small inverse relation between credit quality and the variance of $\log$ price errors. Some of the median parameter estimates for Aaa-rated and Ba-rated firms are substantially different from those for other firms, but there are too few firms in these categories to take the results very seriously.

Panel B of the table confirms the expected relation between the level of default risk and the quality of the firm, as measured by credit rating. This panel reports the median and mean instantaneous default risk estimates for all firms $j$ with a given credit rating in month $t$. These aggregate measures of default risk are monotonically inversely related to credit rating. Firms rated Aaa have a median estimated instantaneous default probability of 0.72 percent; this median estimate rises to 1.66 percent for the Baa firms (the lowest investmentquality grade), and jumps to 2.59 percent for Ba-rated firms (the highest speculative grade). The Panel also reports that the volatility of changes in default probabilities tends to rise as credit quality falls, but this relation is not quite monotonic.

The final issue I investigate in the context of credit ratings is the relation between instantaneous default risk and stock returns. For a given change in a firm's stock price, what is the corresponding change in the firm's default risk implicit in its bond prices? To find out, I regress the monthly change $\hat{h}_{j, t}-\hat{h}_{j, t-1}$ on firm $j$ 's monthly stock return $s_{j, t}$. To account for possibly stale bond prices, I also include three lags of $s_{j, t}$, as indicated in (15) below. The stock returns are from CRSP's AMEX/NYSE monthly tape and are available for only 121 of the 160 firms.

$$
\begin{aligned}
& 100 \Delta \hat{h}_{j, t}=b_{0}+\sum_{i=0}^{3} b_{i+1} s_{j, t}+\eta_{j, t}, \\
& E\left(\eta_{j, t}\right)=0, E\left(\eta_{j, t}^{2}\right)=V, \\
& E\left(\eta_{i, t} \eta_{j, t}\right)=\rho V, i \neq j, E\left(\eta_{i, t} \eta_{j, t-m}\right)=0, m \neq 0, \forall i, j .
\end{aligned}
$$

Models of default risk in the style of Merton (1974) imply that the change in default risk for a given stock-price change is larger for firms that are close to the default boundary than for firms that are far away from the default boundary. To test this hypothesis, as well as to use a more powerful estimation technique than firm-by-firm OLS regressions, I estimate the regressions jointly within a given credit rating. For example, if, at time $t-1$, firm $j$ 's senior unsecured bonds are rated Aa, the observation vector $\left[\Delta \hat{h}_{j, t}, s_{j, t}, s_{j, t-1}, s_{j, t-2}, s_{j, t-3}\right]$ 
is included in the "Aa" panel of data. For Aa, A, and Baa credit ratings, I estimate (15) with quasi-maximum likelihood. (There were too few observations for Aaa-rated or Ba-rated firms to provide reliable estimates.)

The results are displayed in Table 7. Not surprisingly, for all three credit rating categories, stock returns and default probabilities move in opposite directions. Consistent with Merton-type models, the strength of this inverse relation rises as credit quality declines. For example, a one standard deviation positive stock return in month $t$ for a typical Aa-rated firm (which is 6.4 percent for this dataset) corresponds to a decline in the firm's instantaneous default probability of 0.035 percent, with most of this decline occurring in month $t$. For A-rated and Baa-rated firms, the decline in default probabilities is greater and tends to be spread out over the four-month window considered in (15). For example, a one standard deviation stock return in month $t$ for a typical Baa-rated firm (8.2 percent for this dataset) corresponds to a decline in instantaneous default probability of 0.23 percent, half of which occurs after month $t$. Therefore corporate bond prices of lower-rated, investment grade firms appear to be quite stale. Kwan (1996) also finds that corporate bond prices react to stock prices with a lag.

\section{Pricing default portfolio insurance}

We can think of this paper as an exercise in derivative pricing. In particular, if I have correctly specified the stochastic processes for default free interest rates, as well as for firm $j$ 's instantaneous default risk under the equivalent martingale measure, then given the time$t$ price of any one bond issued by firm $j$, I can price any other of the firm's bonds at time $t$. Notwithstanding the fact that in this paper, my success in pricing these other bonds has been limited, this exercise is arguably the simplest practical problem in the universe of credit risk pricing. I are using one type of instrument to price the same type of instrument; they only differ in maturity and, perhaps, coupon payments.

In this section I consider a more difficult pricing problem. One type of credit derivative instrument is a credit default basket swap. The derivative is a type of insurance against the possibility of default by any number of firms. In the particular basket swap considered here, there are two "reference credits," or particular bonds issued by different corporations. If, within three years, either corporation defaults on its particular bond, the credit derivative contract pays $\$ 1$ at the time of default, and the contract expires. If, within three years, neither bond defaults, then the contract expires worthless. What is the fair price of this newly-issued credit default basket swap?

Call the two corporations whose bonds are specified in the contract as Firm 1 and Firm 2. Define $F_{j}$ as a random variable that equals zero if firm $j$ does not default within three years and equals one if it defaults in that time. The value of this derivative clearly depends on the correlation between $F_{1}$ and $F_{2}$. Given the type of model used in this paper, the only source of correlation between $F_{1}$ and $F_{2}$ is a correlation between the innovations in the instantaneous default probabilities $h_{1, t}$ and $h_{2, t}$. Estimating this correlation would require joint estimation of the two firms' stochastic processes. Although in principle this is possible, I bypass this step here by assuming that the correlation is one. I also assume 
that the firms' stochastic processes have identical parameters. This assumption is adopted both for simplicity and to illustrate a point. For now, we can think of these two firms as independent firms in the same industry, so that their prospects are closely related.

I assume that for each firm, their instantaneous default process under the equivalent martingale measure is described by

$$
d h_{i, t}=-0.075 h_{i, t} d t+\sqrt{0.0092 h_{i, t}} d Z_{t}
$$

This process has the median drift given in Panel A in Table 2 and a volatility given by the third quartile in the same panel. I assume the initial instantaneous default probability is 0.01659 , which is the median estimated instantaneous default probability for Baa firms, as shown in Table 6 . These parameters imply that the cumulative probability of default (under the equivalent martingale measure) for either firm over a three-year horizon is 0.05348 . To price this derivative, we also need to model default-free interest rates. We can use the model estimated in Section 4 for this purpose. I set the initial state variables $y_{1,0}$ and $y_{2,0}$ equal to their respective $\theta_{j}$ estimates.

The derivative is priced using Monte Carlo simulations. The price is 0.0955 , but of much more interest is the fact that $\operatorname{cor}\left(F_{1}, F_{2}\right)=0.0301 .{ }^{15}$ Thus, even though the firms' default probabilities move in lockstep, and they are highly volatile (recall that the third quartile value of $\sigma_{j}^{2}$ was chosen), the actual events of default within three years are almost independent. Therefore the price of this instrument when the two firms have identical default probabilities is not much lower than the price when the two firms have independent innovations in default probabilities. ${ }^{16}$ This minimal correlation between $F_{1}$ and $F_{2}$ points to an important weakness in this class of models: They ill-suited to pricing instruments with payoffs that are functions of defaults across multiple firms.

The point is not that the low correlation between $F_{1}$ and $F_{2}$ is necessarily wrong. Rather, it is that this type of model simply cannot produce high correlations between $F_{1}$ and $F_{2}$, even if they are warranted in reality. Examples of pairs of firms with presumably highly correlated default probabilities abound: Two local banks that have essentially the same loan pool (say, commercial real estate loans in Texas), a small firm with one major client, or independent subsidiaries of the same corporation.

Recall that default for firm $j$ is determined by two random variables. The instantaneous probability of default follows an Ito process and the event of default is determined by the first jump of a Poisson event with intensity given by the instantaneous probability of default. The Poisson event is independent of all other variables. Because of the independence of the Poisson processes generating defaults, two firms' default intensities must be both highly correlated and extremely variable to generate anything other than a minimal correlation

\footnotetext{
${ }^{15}$ Because Monte Carlo simulations are used, these values are only approximations. Their standard errors are 0.00013 and 0.00067 respectively.

${ }^{16}$ If we assume that both firms' instantaneous default risk processes are described by (16), but the firms' $d Z$ terms are independent, the price of the credit derivative is 0.0968 (with a Monte Carlo standard error of 0.00016).
} 
between the events of defaults by the two firms. Yet as this example has illustrated, even perfect correlation and relatively large variability in intensities have little effect.

One path out of this difficulty, at least in theory, is to introduce another Poisson event, with its own stochastic intensity process. This Poisson event, if triggered, will cause the simultaneous default of multiple firms. ${ }^{15}$ Unfortunately, such a model appears to be impossible to estimate. There are two problems. The first problem is that comovements in firms' bond prices will be unable to separately identify the stochastic intensity processes for the multiple Poisson events unless an extreme assumption is used, such as assuming independence of the intensity processes associated with the single-firm Poisson events. To illustrate the problem, assume that two firms' bond yields move in lockstep. Is this because the intensities of their independent Poisson default events are identical, as assumed in the pricing exercise above, or because default by either firm always triggers the default of the other firm? The true answer is almost certainly somewhere between these extremes, but corporate bond prices alone cannot distinguish among the various possibilities.

The second problem is that actual default correlations cannot be used to help identify such a model. As discussed in Section 3, the default intensity associated with the Poisson process generating default is not necessarily the true intensity, but rather the intensity under the equivalent martingale measure. Further, as discussed in Section 5, the empirical evidence in this paper indicates that these intensities differ- the risk of default is priced. From the consumption-based asset pricing perspective, it is more likely that the risk of multiple defaults will be priced than will be the risk of single defaults, because states of the world in which multiple defaults occur are more likely to be states in which the economy unexpectedly declines, leading to a fall in consumption. This logic implies that actual default correlations will be lower than default correlations under the equivalent martingale measure.

\section{Concluding remarks}

This paper reports discouraging (albeit preliminary) news. Single-factor models of instantaneous default probabilities, such as the square-root model examined here, face a substantial challenge in matching the dynamic behavior of corporate bond term structures. Models of instantaneous default risk will have to fit both fairly flat term structures of yield spreads when firms have low default risk and relatively steep term structures when firms have higher default risk, but single-factor models do not do this well. Whether multiplefactor models can fit this pattern is not addressed in this paper, but the question is clearly an important one.

Additional discouraging news is that models of instantaneous default risk have a very limited ability to price instruments that have payoffs that depend on the defaults of multiple firms. The basic problem is that in these models, the covariability of firms' corporate bond prices tells us little about the covariability of firms' defaults. (A contrast can be drawn here between such models and Merton-type models, where the covariation of corporate bond prices is informative about the covariation of defaults, since both covariations are driven by the covariation between firms' asset values.)

${ }^{15}$ I am grateful to Dilip Madan for this observation. 
In future empirical work, this analysis should be extended in at least three ways. First, more data on speculative-grade bonds should be included because prices of such bonds should be more responsive to variations in default intensities than prices of investment-grade bonds. (The obvious sticking point is that such prices are typically not measured very accurately owing to limited numbers of transactions.) Second, the behavior of (some set of) firms' default risks should be estimated jointly, both to explicitly investigate the extent to which their default risks covary and to increase the power of the statistics. Maximum likelihood may prove infeasible in this situation, hence an alternative estimation technique such as the Kalman filter methodology of Duan and Simonato (1995) and Chen and Scott (1995) may be required. Third, multifactor models of default risk should be estimated to see if such specifications can circumvent the types of misspecification that this paper finds in a single-factor model. However, the data requirements (i.e., the number of bonds observed in the cross-section) for accurate estimation of multifactor models are very large compared to the amount of data available for a typical firm, so it is unclear whether such models can be successfully estimated at the firm level. 


\section{Appendix 1. Bond price equations}

The default-free instantaneous interest rate process in (3) implies the following zerocoupon bond prices.

$$
\begin{aligned}
P\left(t, T, 0 ; y_{1, t}, y_{2, t}\right)=A_{1}(t, T) A_{2}(t, T) e^{-B_{1}(t, T) y_{1, t}-B_{2}(t, T) y_{2, t}} & \\
A_{i}(t, T) & =\left[\frac{2 \gamma_{i} \exp \left[\left(\kappa_{i}+\lambda_{i}+\gamma_{i}\right)(T-t) / 2\right]}{\left(\gamma_{i}+\kappa_{i}+\lambda_{i}\right)\left(\exp \left[\gamma_{i}(T-t)\right]-1\right)+2 \gamma_{i}}\right]^{2 \kappa_{i} \theta_{i} / \sigma_{i}^{2}} \\
B_{i}(t, T) & =\frac{2\left\{\exp \left[\gamma_{i}(T-t)\right]-1\right\}}{\left(\gamma_{i}+\kappa_{i}+\lambda_{i}\right)\left(\exp \left[\gamma_{i}(T-t)\right]-1\right)+2 \gamma_{i}}, \\
\gamma_{i} & =\left[\left(\kappa_{i}+\lambda_{i}\right)^{2}+2 \sigma_{i}^{2}\right]^{1 / 2}
\end{aligned}
$$

The default-free instantaneous interest rate process and the instantaneous default process (6) imply the following zero-coupon corporate bond prices with no recovery in default.

$$
\begin{aligned}
& V\left(t, T, 0,0 ; y_{1, t}, y_{2, t}, h_{j, t}\right)= \\
& A_{1}(t, T) A_{2}(t, T) A_{j}(t, T) e^{-B_{1}(t, T) y_{1, t}-B_{2}(t, T) y_{2, t}-B_{j}(t, T) h_{j, t}}
\end{aligned}
$$

where $A_{j}(t, T)$ and $B_{j}(t, T)$ are functions as in (A2) with $j$ in place of $i$.

I use $P(t, T, c)$ to denote the price of a default-free bond that pays a coupon $c$ at $T$ (in addition to the principal payment) and every six months prior to $T$. Similarly, denote the price of a default-risky bond issued by firm $j$ that promises a semiannual coupon $c$, but pays nothing in default, as $V_{j}(t, T, c, 0)$. Simple no-arbitrage arguments reveal that the price of a coupon bond is the sum of the prices of the individual coupon payments and principal payment.

Finally, consider a coupon bond issued by firm $j$, maturing at time $T$, with recovery rate $\delta$. Denote its price by $V_{j}(t, T, c, \delta)$. I assume that in the event of default at time $\tau$, the bond pays off $\delta P(\tau, T, c)$. (This is equivalent to assuming the bond pays $\delta c$ at each coupon payment date after default, and an additional $\delta$ at maturity.) Given this assumption, a modification of (7) will hold:

$$
V_{j}(t, T, c, \delta)=\delta P(t, T, c)+(1-\delta) V_{j}(t, T, c, 0)
$$

Therefore default-risky coupon bonds with recovery can be priced in terms of the equivalent martingale default-free rate processes (3) and the default intensity process (6). 


\section{Appendix 2. Estimation Details}

\section{2.a. Estimation of the default-free process}

Month $t$ 's observations of $\log$ bond prices are $p\left(t, T_{i, t}, c_{i, t}\right), i=1, \ldots, 7$, where $T_{i, t}$ and $c_{i, t}$ are the maturity and coupon that identify the $i^{t h}$ bond. Two log bond prices are assumed to be observed without error. Order the bonds so that these bonds are the first two. Then we have

$$
\begin{gathered}
p\left(t, T_{i, t}, c_{i, t}\right)=\log P\left(t, T_{i, t}, c_{i, t} ; y_{1, t}, y_{2, t}\right), \quad i=1,2 ; \\
p\left(t, T_{i, t}, c_{i, t}\right)=\log P\left(t, T_{i, t}, c_{i, t} ; y_{1, t}, y_{2, t}\right)+\epsilon(t, i), \quad i=3, \ldots, 7 \\
\epsilon(t, i) \sim N\left(0, S_{i}^{2}\right)
\end{gathered}
$$

Denote the joint density of month $t$ 's log bond prices conditional on month $t-1$ 's $\log$ bond prices as $g_{t}$. Denote the determinant of the Jacobian of $\log P\left(t, T_{i, t}, c_{i, t}\right)$ for $i=1,2$ with respect to the state variables as $D_{t}$. Then the joint density $g_{t}$ can be written in terms

of $D_{t}$, the conditional densities of the independent state variables, and the densities of the independent measurement errors:

$$
g_{t}=\left|D_{t}\right|^{-1} f\left(y_{1, t} \mid y_{1, t-1}\right) f\left(y_{2, t} \mid y_{2, t-1}\right) \prod_{i=3}^{7}\left(2 \pi S_{i}^{2}\right)^{-1 / 2} \exp \left\{-\frac{1}{2} \frac{\epsilon(t, i)^{2}}{S_{i}^{2}}\right\}
$$

where $f\left(y_{i, t} \mid y_{i, t-1}\right)$ is the density of $y_{i, t}$ conditional on $y_{i, t-1}$. Denote the modified Bessel function of the first kind of order $q$ by $I_{q}(\cdot)$. The conditional density of $y_{i, t}$ is

$$
\begin{aligned}
f\left(y_{i, t} \mid y_{i, t-1}\right) & =s_{i} e^{-u_{i}-v_{i}}\left(\frac{v_{i}}{u_{i}}\right)^{q_{i} / 2} I_{q_{i}}\left[2\left(u_{i} v_{i}\right)^{1 / 2}\right] \\
s_{i} & \equiv \frac{2 \kappa_{i}}{\sigma_{i}^{2}\left[1-\exp \left(-\kappa_{i} / 12\right)\right]} \\
q_{i} & \equiv \frac{2 \kappa_{i} \theta_{i}}{\sigma_{i}^{2}}-1 \\
u_{i} & \equiv s_{i} y_{i, t-1} \exp \left(-\kappa_{i} / 12\right) \\
v_{i} & \equiv s_{i} y_{i, t} .
\end{aligned}
$$

The $\log$ of the joint density of all 119 observations conditioned on the January 1985 observation is

$$
L=\sum_{t=2}^{120} \log g_{t}
$$

I choose the parameters of the default-free process to maximize (A7). I do not include the unconditional density of the January 1985 observation in (A7) because I am unwilling to assume stationarity of both $y_{1, t}$ and $y_{2, t}$. 
For a given set of parameters $\kappa_{i}, \theta_{i}, \lambda_{i}, \sigma_{i}^{2}, i=1,2$ and $S_{i}^{2}, i=3, \ldots, 7$, I calculate (A7) as follows. The prices observed without error in month $t$ are used to compute numerically month $t$ 's state variables $y_{1, t}$ and $y_{2, t}$. (If we were working with zero-coupon bonds, the bond price equation (A1) could be inverted to produce a closed-form solution for the state variables, but this is not possible with coupon bond prices.) If either state variable is negative, the $\log$ conditional density for month $t$ is set to a large negative value, with the precise value depending on the magnitude(s) of the negative state variable(s). If the state variables are positive, the $\log$ conditional density for month $t$ is evaluated. In practice, I rewrite the density $f\left(y_{i, t} \mid y_{i, t-1}\right)$ as

$$
f\left(y_{i, t} \mid y_{i, t-1}\right)=s_{i} e^{\left[2\left(u_{i} v_{i}\right)^{1 / 2}-u_{i}-v_{i}\right]}\left(\frac{v_{i}}{u_{i}}\right)^{q_{i} / 2}\left\{e^{-2\left(u_{i} v_{i}\right)^{1 / 2}} I_{q_{i}}\left[2\left(u_{i} v_{i}\right)^{1 / 2}\right]\right\}
$$

The final term in curly brackets in (A8) is evaluated using NAG agorithms S18DEF and S18DCF. (Numerical approximations to $e^{-x} I_{q}(x)$ are much more stable than approximations to $I_{q}(x)$.) Finally, the monthly log conditional densities are summed as in (A7).

A preliminary maximum to (A7) is estimated using the Simplex method (NAG routine E04CCF). From this point, a sequential quadratic programming method is used (NAG routine E04UCF). Analytic first derivatives are used everywhere except for $\partial I_{q}(x) / \partial q$, where a robust numerical method is used.

\section{2.b. Estimation of the default risk processes}

The default risk process for firm $j$ is estimated taking as given the default-free processes $y_{1, t}$ and $y_{2, t}$. Firm $j$ has $M_{j, t}$ bonds with observed prices in month $t$. The logs of the observed bond prices are denoted $v_{j}\left(t, T_{j, i, t}, c_{j, i, t}\right), i=1, M_{j, t}$, where $T_{j, i, t}$ and $c_{j, i, t}$ are the maturity and coupon that identify the bond. One of these observations is made without error, while the others are contaminated with normally distributed, iid measurement error with variance $S_{j}^{2}$. The bonds are ordered so that the first is observed without error. Then we have

$$
\begin{gathered}
v_{j}\left(t, T_{j, 1, t}, c_{j, 1, t}\right)=\log V\left(t, T_{j, 1, t}, c_{j, 1, t}, \delta ; y_{1, t}, y_{2, t}, h_{j, t}\right), \\
v_{j}\left(t, T_{j, i, t}, c_{j, i, t}\right)= \\
\log V\left(t, T_{j, i, t}, c_{j, i, t}, \delta ; y_{1, t}, y_{2, t}, h_{j, t}\right)+\epsilon_{j}(t, i), \quad i=2, \ldots, M_{j, t} \\
\epsilon_{j}(t, i) \sim N\left(0, S_{j}^{2}\right) \forall i
\end{gathered}
$$

Month $t$ is a valid observation for firm $j$ if $M_{j, t}>1$ and $M_{j, t-1}>0$. These inequalities ensure that the state variable $h$ is observed in both months $t$ and $t-1$, while measurement error is also present in month $t$. Therefore for these months the conditional density of month $t$ 's $\log$ prices can be evaluated.

Denote the density of month $t$ 's $\log$ bond prices conditional on month $t-1$ 's $\log$ prices (as well as on the default-free process values $y_{1, t-1}, y_{2, t-1}, y_{1, t}$, and $y_{2, t}$ ) as $g_{j, t}$. Denote 
the derivative of $\log V\left(t, T_{j, 1, t}, c_{j, 1, t}, \delta ; y_{1, t}, y_{2, t}, h_{j, t}\right)$ with respect to $h_{j, t}$ as $D_{j, t}$. Then the density $g_{j, t}$ can be written as

$$
g_{j, t}=\left|D_{j, t}\right|^{-1} f\left(h_{j, t} \mid h_{j, t-1}\right)\left(2 \pi S_{j}^{2}\right)^{-\left(M_{j, t}-1\right) / 2} \prod_{i=2}^{M_{j, t}} \exp \left\{-\frac{1}{2} \frac{\epsilon_{j}(t, i)^{2}}{S_{j}^{2}}\right\}
$$

where $f\left(h_{j, t} \mid h_{j, t-1}\right)$ is the appropriate analogue of (A6).

Denote the valid observations for firm $j$ by $\tau_{i}, i=1, \ldots, N_{j}$. Then the log-likelihood for firm $j$ conditioned on the firm's bond prices at time $\tau_{1}-1$ is

$$
L_{j}=\sum_{i=1}^{N_{j}} \log g_{j, \tau_{i}}
$$

As with the default-free log-likelihood function, the unconditional distribution of the first observation is not included because I am unwilling to impose stationarity of $h_{j, t}$.

I evaluate and maximize (A11) in a manner similar to that for (A7). The only important difference is that I use repeated applications of the Simplex method to maximize (A11) instead of also using a derivative-based method. For many firms, first derivatives blow up for parameter values near the optimum parameter values. 


\section{Appendix 3. List of firms}

AIR PRODUCTS \& CHEMICALS

ALLIED - SIGNAL INC

ALLIED CORP

AMERICAN EXPRESS CREDIT

AMERICAN GENERAL FIN CORP

AMR CORPORATION

ANADARKO PETROLEUM

ANHEUSER-BUSCH CO.,INC.

ARCHER-DANIELS-MIDLAND

ARCO CHEMICAL CO

ARISTAR INC

ARKLA INC.

ASSOCIATES CORP NO AMER

ATLANTIC RICHFIELD

AVCO FINANCIAL SERVICES

BALTIMORE GAS + ELEC

BANKAMERICA CORP

BANKERS TRUST NY

BAXTER INTERNATIONAL INC

BEAR STEARNS CO, INC

BECTON, DICKINSON \& CO.

BENEFICIAL CORP

BOISE CASCADE CORP

BOWATER

BP AMERICA INC

BURLINGTON RESOURCES INC

CAROLINA POWER + LIGHT

CATERPILLAR INC

CHAMPION INTL

CHASE MANHATTAN CORP

CHATTANOOGA VALLEY CORP

CHEMICAL BANKING CORP

CHESAPEAKE + OHIO RY CO

CHRYSLER FINANCIAL

CIT GROUP HOLDINGS

CITICORP

CITY INVESTING CO

CNA FINANCIAI

COASTAL CORPORATION

COCA - COLA ENTERPRISES INC.

COCA-COLA CO

COMDISCO INC

COMMERCIAL CREDIT

COMMONWEALTH EDISON

CONAGRA INC

CONSOLIDATED NATURAL GAS

CORESTATES CAPITAL CORP

CORNING GLASS WORKS

CSX CORP

DAYTON HUDSON CORP

DEERE + CO

DEERE JOHN CAPITAL CORP

DELTA AIRLINES, INC.

DILLARD DEPARTMENT STORES
DONNELLEY R.R. \& SONS CO

DOW CHEMICAL

DOW CHEMICAL B.V.

DUPONT E I DE NEMOURS

EASTMAN KODAK COMPANY

EL PASO NATURAL GAS

ENRON CORP

EXXON CAPITAL CORP

FEDERAL EXPRESS CORP

FIRST CHICAGO CORP

FIRST INTERSTATE BANCORP

FIRST UNION CORPORATION

FLEET/NORSTAR FIN GROUP

FORD CAPITAL B.V.

FORD MOTOR

FORD MOTOR CREDIT

GENERAL ELECTRIC

GENERAL ELECTRIC CAPITAL

GENERAL MOTORS

GENERAL MOTORS ACPT CORP

GEORGIA PACIFIC

GOLDEN WEST FIN. CORP (DEL)

GREAT WESTERN BANK

GTE CORP

HELLER FINANCIAL, INC

HERTZ CORP

HOUSEHOLD FINANCE

HOUSTON INDUSTRIES INC

ICI WILMINGTON

INGERSOLL RAND

INTERNATIONAL LEASE FINAN

INTERNATIONAL PAPER

ITT CORPORATION

ITT FINANCIAL

JAMES RIVER CORP

K MART

KIDDE, INC.

KIMBERLY CLARK

LOCKHEED CORPORATION

LONG ISLAND LIGHTING

LYONDELL PETROCHEMICAL

MANUFACT HANOVER CORP

MARRIOTT CORPORATION

MARTIN MARIETTA

MAY DEPARTMENT STORES

MAYTAG CORPORATION

MELLON FINANCIAL CO.

MERRILL LYNCH \& CO.

MOBIL CORP

MORGAN J P INC

MORGAN STANLEY GROUP INC

NCNB CORP

NIAGARA MOHAWK POWER
NORWEST FINANCIAL INC. OCCIDENTAL PETROLEUM OHIO EDISON

PENNEY J C

PENNZOIL COMPANY

PEPSICO INC

PHILADELPHIA ELECTRIC CO

PHILIP MORRIS COS. INC

PHILLIPS PETROLEUM

PROCTER + GAMBLE CO

PUB SVC ELECTRIC + GAS

RALSTON PURINA CO

REP NATIONAL BK OF N.Y.

REPUBLIC NEW YORK CORP

RJR NABISCO, INC

ROCKWELL INTERNATIONAL

SALOMON INC

SCOTT PAPER

SEAGRAM CO LTD

SEAGRAM JOSEPH E + SONS

SEARS ROEBUCK + CO

SECURITY PACIFIC CORP

SHEARSON LEHMAN HLDINGS

SHEARSON LEHMAN HUTTON INC

SHELL OIL CO

SOUTHERN CALIF EDISON

SOUTHWEST AIRLINES CO.

SOUTHWESTERN BELL TEL

SUNTRUST BANKS, INC

TENNECO CREDIT CORP

TENNECO INC

TENNESSEE GAS PIPELINE CO

TEXACO CAPITAL INC.

TEXAS EASTERN TRANSMISSN

TIMES MIRROR

TRANSAMERICA CORP

TRANSAMERICA FINANCIAL

TRANSCO ENERGY CO

UNION CAMP

UNION OIL OF CALIFORNIA

UNION PACIFIC CORP

UNITED AIR LINES INC

USX CORP

UTILICORP UNITED INC

VIRGINIA ELECTRIC POWER

WAL-MART STORES, INC

WASTE MANAGEMENT, INC.

WELLS FARGO + CO

WESTINGHOUSE ELECTRIC

WEYERHAEUSER CO

WILLIAMS COS

XEROX CORP

XEROX CREDIT CORP 


\section{References}

Ball, Clifford A., and Walter N. Torous, 1996, "Unit roots and the estimation of interest rate dynamics," Journal of Empirical Finance 3, 215-238.

Chen, Ren-raw, and Louis Scott, 1993, "Maximum likelihood estimation for a multifactor equilibrium model of the term structure of interest rates," Journal of Fixed Income 3, $14-31$.

Chen, Ren-raw, and Louis Scott, 1995, "Multi-factor Cox-Ingersoll-Ross models of the term structure: Estimates and tests from a Kalman filter model," Working paper, University of Georgia (Athens, GA).

Cox, John C., Jonathan E. Ingersoll Jr., and Stephen A. Ross, 1985, "A theory of the term structure of interest rates," Econometrica 53, 385-407.

Das, Sanjiv Ranjan and Peter Tufano, 1995, "Pricing credit-sensitive debt when interest rates, credit ratings and credit spreads are stochastic," Working paper, Harvard Business School (Boston, MA).

Davidian, Marie and Raymond J. Carroll, 1987, "Variance function estimation," Journal of the American Statistical Association 65, 1509-1526.

Duan, Jin-Chuan, and Jean-Guy Simonato, 1995, "Estimating and testing exponentialaffine term structure models by Kalman filter," Working paper, McGill University (Montreal, CA).

Duffee, Gregory R., 1996, "Treasury yields and corporate bond yield spreads: An empirical analysis," Working paper, Federal Reserve Board (Washington, DC).

Duffie, Darrell, 1996, Dynamic Asset Pricing Theory, Princeton University Press, Princeton, NJ.

Duffie, Darrell, and Ming Huang, 1996, "Swap rates and credit quality," Journal of Finance 51, 921-949.

Duffie, Darrell, and Kenneth J. Singleton, 1995a, "Modeling term structures of defaultable bonds," Working paper, Stanford Graduate School of Business (Stanford, CA). 
Duffie, Darrell, and Kenneth J. Singleton, 1995b, "An econometric model of the term structure of interest rate swap yields," Working paper, Stanford Graduate School of Business (Stanford, CA).

Fons, Jerome S., 1994, "Using default rates to model the term structure of credit risk," Financial Analysts Journal, September/October, 25-32.

Fons, Jerome S., Lea Carty, and Jeremy Kaufman, 1994, "Corporate bond defaults and default rates 1970-1993," Moody's Special Report, January.

Grinblatt, Mark, 1995, "An analytical solution for interest rate swap spreads," Working paper, UCLA (Los Angeles, CA).

Helwege, Jean and Christopher M. Turner, 1995, "The slope of the credit yield curve for speculative-grade issuers," Working paper, Federal Reserve Bank of New York.

Jarrow, Robert, David Lando, and Stuart Turnbull, 1994, "A Markov model for the term structure of credit risk spreads," Working paper, Cornell University (Ithaca, NY).

Jarrow, Robert A., and Stuart M. Turnbull, 1995, "Pricing derivatives on financial securities subject to credit risk," Journal of Finance 50, 53-86.

Jones, E. Phillip, Scott P. Mason, and Eric Rosenfeld, 1984, "Contingent claims analysis of corporate capital structures: An empirical investigation," Journal of Finance 39, 611-625.

Kwan, Simon H., 1996, "Firm-specific information and the correlation between individual stocks and bonds," Journal of Financial Economics 40, 63-80.

Lando, David, 1994, "On Cox processes and credit risky bonds," Working paper, Institute of Mathematical Statistics, University of Copenhagen.

Litterman, Robert and Thomas Iben, 1991, "Corporate bond valuation and the term structure of credit spreads," Journal of Portfolio Management, Spring, 52-64.

Longstaff, Francis A. and Eduardo S. Schwartz, 1995, "A simple approach to valuing risky fixed and floating rate debt," Journal of Finance 50, 789-820.

Madan, Dilip B. and Haluk Unal, 1994, "Pricing the risks of default," Working paper, Wharton (Philadelphia, PA). 
Merton, Robert C., 1974, "On the pricing of corporate debt: The risk structure of interest rates," The Journal of Finance 29, 449-470.

Madan, Dilip B. and Haluk Unal, 1994, "Pricing the risks of default," Working paper, Wharton (Philadelphia, PA).

Nielsen, Soren S., and Ehud I. Ronn, 1996, "The valuation of default risk in corporate bonds and interest rate swaps," Working paper, University of Texas at Austin (Austin, TX).

Sarig, Oded and Arthur Warga, 1989, "Some empirical estimates of the risk structure of interest rates," Journal of Finance 44, 1351-1360.

Schwert, G. William, 1989, "Tests for unit roots: A Monte Carlo investigation," Journal of Business and Economic Statistics 7, 147-159.

Sorensen, Eric H., and Thierry F. Bollier, 1994, "Pricing swap default risk," Financial Analysts Journal, May-June, 23-33.

Warga, Arthur D., 1991, "Corporate bond price discrepancies in the dealer and exchange markets," Journal of Fixed Income 1, 7-16.

Zhou, Chunsheng, 1996, "A jump-diffusion approach to modeling credit risk and valuing defaultable securities," Working paper, Federal Reserve Board (Washington, DC). 
Table 1

Maximum likelihood estimates of a two factor square-root model of Treasury bond yields

\begin{tabular}{ccccccc}
$d y_{i, t}=\kappa_{i}\left(\theta_{i}-y_{i, t}\right) d t+\sigma_{i} \sqrt{y_{i, t}} d Z_{i, t}$ & (true measure) \\
& $d y_{i, t}=\left(\kappa_{i} \theta_{i}-\left(\kappa_{i}+\lambda_{i}\right) y_{i, t}\right) d t+\sigma_{i} \sqrt{y_{i, t}} d \hat{Z}_{i, t}$ & \multicolumn{2}{l}{ (martingale measure) } \\
& \multicolumn{1}{c}{${ }^{2}$} & & & & \\
\hline & $\kappa_{i}$ & $\theta_{i}\left(\times 10^{2}\right)$ & $\lambda_{i}$ & $\sigma_{i}^{2}\left(\times 10^{2}\right)$ & $\kappa_{i} \theta_{i}\left(\times 10^{2}\right)$ & $\kappa_{i}+\lambda_{i}$ \\
\hline 1 & 0.674 & 3.964 & -0.214 & 0.724 & 2.672 & 0.461 \\
& $(0.239)$ & $(1.392)$ & $(0.235)$ & $(0.141)$ & $(0.083)$ & $(0.014)$ \\
2 & 0.184 & 0.286 & -0.205 & 0.419 & 0.053 & -0.021 \\
& $(0.129)$ & $(0.203)$ & $(0.129)$ & $(0.040)$ & $(0.008)$ & $(0.005)$
\end{tabular}

\begin{tabular}{|c|c|c|}
\hline Maturity & $\begin{array}{l}\text { Est. variance of } \\
\text { measurement error } \\
\left(\times 10^{4}\right)\end{array}$ & $\begin{array}{l}\text { RMSE of yield } \\
\text { to maturity }{ }^{a} \\
\text { (basis points) }\end{array}$ \\
\hline 6 mon & $\begin{array}{c}0.013 \\
(0.002)\end{array}$ & 27.3 \\
\hline 3 year & $\begin{array}{c}0.089 \\
(0.015)\end{array}$ & 11.0 \\
\hline 5 year & $\begin{array}{c}0.351 \\
(0.071)\end{array}$ & 14.7 \\
\hline 7 year & $\begin{array}{c}0.486 \\
(0.086)\end{array}$ & 13.7 \\
\hline 30 year & $\begin{array}{c}1.730 \\
(0.193)\end{array}$ & 11.0 \\
\hline
\end{tabular}

The instantaneous default-free interest rate is $r_{t}=y_{1, t}+y_{2, t}$. Prices of one-year and ten-year Treasury coupon bonds are assumed to be observed without error. Log prices of Treasury coupon bonds with maturities of approximately six months, three years, five years, seven years, and 30 years are assumed to be contaminated with normally distributed, iid measurement errors. The estimated parameters maximize the sum, over January 1985 through December 1994, of the log likelihood of the the joint density of month $t+1$ 's $\log$ prices conditional on month $t$ 's log prices. Standard errors are in parentheses.

a The square root of the mean (across 120 monthly observations) of the squared difference between the actual yield to maturity on the bond and the bond's yield to maturity implied by the model. 
Table 2

Summary of maximum likelihood estimates of 160 firms' default risk processes implied by corporate bond term structures

\begin{tabular}{|c|c|c|c|c|}
\hline \multicolumn{3}{|c|}{$\begin{array}{l}d h_{j, t}=\kappa_{j}\left(\theta_{j}-h_{j, t}\right) d t+\sigma_{j} \sqrt{h_{j, t}} d Z_{j, t} \\
d h_{j, t}=\left(\kappa_{j} \theta_{j}-\left(\kappa_{j}+\lambda_{j}\right) h_{j, t}\right) d t+\sigma_{j} \sqrt{h_{j, t}} d \hat{Z}_{j, t}\end{array}$} & \multicolumn{2}{|c|}{$\begin{array}{l}\text { (true measure) } \\
\text { (martingale measure) }\end{array}$} \\
\hline Variable & Scale $^{a}$ & $1^{\text {st }}$ quartile & Median & $3^{r d}$ quartile \\
\hline Panel A: & \multicolumn{4}{|c|}{ Longest maturity bond observed without error } \\
\hline$\kappa_{j}$ & - & 0.000 & 0.000 & 0.085 \\
\hline$\theta_{j}$ & $10^{2}$ & -0.128 & 0.000 & 0.651 \\
\hline$\lambda_{j}$ & - & -0.200 & -0.098 & -0.043 \\
\hline$\sigma_{j}^{2}$ & $10^{2}$ & 0.254 & 0.465 & 0.920 \\
\hline$\kappa_{j} \theta_{j}$ & $10^{2}$ & 0.000 & 0.000 & 0.068 \\
\hline$\kappa_{j}+\lambda_{j}$ & - & -0.123 & -0.075 & -0.018 \\
\hline$S_{j}^{2}$ & $10^{4}$ & 0.271 & 0.540 & 1.031 \\
\hline Mean fitted $h_{j, t}$ & $10^{2}$ & 0.977 & 1.299 & 1.732 \\
\hline $\begin{array}{l}\text { RMSE of yield to } \\
\text { maturity (b.p.) }\end{array}$ & - & 14.850 & 18.365 & 24.628 \\
\hline $\begin{array}{l}\text { Mean implied equivalent } \\
\text { martingale } 5 \text { yr default prob. }\end{array}$ & - & 0.059 & 0.079 & 0.102 \\
\hline Panel B: & \multicolumn{4}{|c|}{ Bond closest to five years observed without error } \\
\hline$\kappa_{j}$ & - & 0.013 & 0.127 & 0.343 \\
\hline$\theta_{j}$ & $10^{2}$ & 0.486 & 1.122 & 2.380 \\
\hline$\lambda_{j}$ & - & -0.238 & -0.116 & -0.040 \\
\hline$\sigma_{j}^{2}$ & $10^{2}$ & 0.635 & 1.045 & 1.545 \\
\hline$\kappa_{j} \theta_{j}$ & $10^{2}$ & 0.086 & 0.205 & 0.358 \\
\hline$\kappa_{j}+\lambda_{j}$ & - & -0.057 & 0.028 & 0.139 \\
\hline$S_{j}^{2}$ & $10^{4}$ & 0.386 & 0.910 & 1.816 \\
\hline Mean fitted $h_{j, t}$ & $10^{2}$ & 0.963 & 1.360 & 1.730 \\
\hline $\begin{array}{l}\text { RMSE of yield to } \\
\text { maturity (b.p.) }\end{array}$ & - & 13.492 & 16.609 & 22.486 \\
\hline $\begin{array}{l}\text { Mean implied equivalent } \\
\text { martingale } 5 \text { yr default prob. }\end{array}$ & - & 0.065 & 0.080 & 0.101 \\
\hline
\end{tabular}

Firm $j$ 's instantaneous probability of default is denoted $h_{j, t}$. In each month the price of one of firm $j$ 's bonds is assumed to be observed without error. All other log prices of firm $j$ 's bonds are observed with idd normally distributed measurement error with variance $S_{j}^{2}$. For each of 160 firms, this model is estimated with maximum likelihood, using the one-month transition densities of log bond prices. The data set covers January 1985 through December 1994.

a The displayed estimates have been multiplied by the scale factor (if any).

$b$ The square root of the mean of the squared differences between the actual and fitted yields to maturity on firm $j$ 's bonds that are observed with error (expressed in basis points). 
Table 3

Summary of Augmented Dickey-Fuller tests of firms' estimated instantaneous default probabilities

\begin{tabular}{|c|c|c|c|}
\hline Variable & $1^{s t}$ quartile & Median & $3^{r d}$ quartile \\
\hline \multicolumn{4}{|c|}{ Panel A: Longest maturity bond observed without error } \\
\hline Num. of Obs. & 42.000 & 52.000 & 80.250 \\
\hline$b_{1}$ & -0.251 & -0.173 & -0.110 \\
\hline$t$ stat of $b_{1}$ & -2.78 & -2.20 & -1.74 \\
\hline$b_{2}$ & -0.034 & 0.051 & 0.185 \\
\hline$t$ stat of $b_{2}$ & -0.24 & 0.38 & 1.25 \\
\hline$b_{3}$ & -0.110 & -0.006 & 0.064 \\
\hline$t$ stat of $b_{3}$ & -0.81 & -0.04 & 0.52 \\
\hline$S E E\left(\times 10^{2}\right)$ & 0.145 & 0.207 & 0.309 \\
\hline Std. Dev. of $\Delta h_{j, t}\left(\times 10^{2}\right)$ & 0.164 & 0.229 & 0.328 \\
\hline \multicolumn{4}{|c|}{ Panel B: Bond closest to five years observed without error } \\
\hline$b_{1}$ & -0.308 & -0.202 & -0.142 \\
\hline$t$ stat of $b_{1}$ & -3.07 & -2.44 & -1.94 \\
\hline$b_{2}$ & -0.008 & 0.104 & 0.211 \\
\hline$t$ stat of $b_{2}$ & -0.05 & 0.77 & 1.57 \\
\hline$b_{3}$ & -0.062 & 0.046 & 0.116 \\
\hline$t$ stat of $b_{3}$ & -0.49 & 0.29 & 0.90 \\
\hline$S E E\left(\times 10^{2}\right)$ & 0.236 & 0.296 & 0.397 \\
\hline Std. Dev. of $\Delta h_{j, t}\left(\times 10^{2}\right)$ & 0.255 & 0.319 & 0.432 \\
\hline
\end{tabular}

Firm $j$ 's estimated instantaneous probability of default at month-end $t$ is denoted $\hat{h}_{j, t}$. These estimates are produced assuming either that a long-maturity bond price is measured without error (Panel A) or that a five-year bond price is measured without error (Panel B.) An ADF test (two lags) is estimated for each of 160 firms. Summaries of the parameter estimates are reported above. 
Table 4

Specification tests of the predictability of estimated shocks to firms' instantaneous default probabilities

$$
\begin{gathered}
\epsilon_{j, t}=b_{0}+\sum_{i=0}^{3} b_{i+1}[\text { Regressor }]_{t-i}+\eta_{j, t}, \\
E\left(\eta_{j, t}\right)=0, E\left(\eta_{j, t}^{2}\right)=V, E\left(\eta_{i, t} \eta_{j, t}\right)=\rho V, i \neq j, E\left(\eta_{i, t} \eta_{j, t-m}\right)=0, m \neq 0, \forall i, j .
\end{gathered}
$$

\begin{tabular}{cccrrrrrrrr}
\hline $\begin{array}{c}\text { Regression } \\
\text { number }\end{array}$ & $\begin{array}{c}\text { Right hand } \\
\text { side variable }\end{array}$ & $\begin{array}{c}\text { Num. of } \\
\text { Obs. }\end{array}$ & Intercept & $\operatorname{Lag} 0$ & $\operatorname{Lag} 1$ & $\operatorname{Lag} 2$ & $\operatorname{Lag} 3$ & $\rho$ & $V$ \\
\hline \multirow{2}{*}[1]{} & $\epsilon_{j, t}$ & 9466 & 0.104 & - & -0.094 & -0.058 & -0.026 & 0.243 & 1.245 \\
& & & $(2.01)$ & & $(-5.14)$ & $(-2.72)$ & $(-1.95)$ & $(8.08)$ & $(2.08)^{a}$ \\
{$[2]$} & $\Delta Y_{30 y r}$ & 10041 & 0.077 & -0.628 & 0.265 & 0.209 & 0.075 & 0.243 & 1.245 \\
& & & $(1.59)$ & $(-3.30)$ & $(1.63)$ & $(1.33)$ & $(0.53)$ & $(7.68)$ & $(2.11)^{a}$ \\
{$[3]$} & $\Delta\left(Y_{30 y r}-Y_{3 m o n}\right)$ & 10041 & 0.080 & -0.022 & -0.043 & 0.220 & 0.102 & 0.223 & 1.268 \\
& & & $(1.57)$ & $(-0.09)$ & $(0.26)$ & $(1.01)$ & $(0.63)$ & $(8.66)$ & $(2.27)^{a}$
\end{tabular}

$\epsilon_{j, t}$ is the estimated normalized innovation in firm $j$ 's estimated probability of default from $t-1$ to $t$, based on the assumption that the price of the firm's long bond at time $t$ is measured without error. $Y_{30 y r}$ denotes the 30-year constant maturity Treasury yield. $Y_{3 m o n}$ denotes the three-month Treasury bill yield. If the model is specified correctly, $\epsilon_{j, t}$ should follow a random walk and be unforecastable with either current or lagged of changes in default-free interest rates. The regressions are estimated jointly across all 160 firms using quasi-maximum likelihood. $T$-statistics are in parentheses.

\footnotetext{
${ }^{a} T$-statistic versus one.
} 
Table 5

Specification tests of the predictability of the volatility of estimated shocks to firms' instantaneous default probabilities

$$
\begin{gathered}
\text { volatility }_{j, t}=b_{0}+\sum_{i=1}^{3} b_{i} \text { volatility }_{j, t-i}+b_{4} \hat{h}_{j, t-1}+\eta_{j, t}, \\
E\left(\eta_{j, t}\right)=0, E\left(\eta_{j, t}^{2}\right)=V, E\left(\eta_{i, t} \eta_{j, t}\right)=\rho V, i \neq j, E\left(\eta_{i, t} \eta_{j, t-m}\right)=0, m \neq 0, \forall i, j .
\end{gathered}
$$

\begin{tabular}{|c|c|c|c|c|c|c|c|c|}
\hline $\begin{array}{l}\text { Volatility } \\
\text { Measure }\end{array}$ & $\begin{array}{c}\text { Num. of } \\
\text { Obs. }\end{array}$ & Intercept & Lag 1 & $\begin{array}{l}\text {-Volatilit } \\
\text { Lag } 2\end{array}$ & Lag 3 & $h_{j, t}$ & $\rho$ & V \\
\hline$\epsilon_{j, t}^{2}$ & 9466 & $\begin{array}{l}1.178 \\
(6.86)\end{array}$ & $\begin{array}{r}0.021 \\
(2.50)\end{array}$ & $\begin{array}{r}0.002 \\
(4.90)\end{array}$ & $\begin{array}{l}-0.001 \\
(-2.10)\end{array}$ & $\begin{array}{r}6.496 \\
(1.26)\end{array}$ & $\begin{array}{r}0.019 \\
(2.42)\end{array}$ & $\begin{array}{r}61.421 \\
(2.02)\end{array}$ \\
\hline$\left|\epsilon_{j, t}\right|$ & 9466 & $\begin{array}{r}0.572 \\
(16.96)\end{array}$ & $\begin{array}{r}0.113 \\
(8.31)\end{array}$ & $\begin{array}{r}0.039 \\
(4.10)\end{array}$ & $\begin{array}{c}0.020 \\
(1.65)\end{array}$ & $\begin{array}{r}2.447 \\
(2.86)\end{array}$ & $\begin{array}{r}0.110 \\
(4.72)\end{array}$ & $\begin{array}{c}0.714 \\
(8.17)\end{array}$ \\
\hline
\end{tabular}

$\epsilon_{j, t}$ is the estimated normalized innovation in $\hat{h}_{j, t}$, which is firm $j$ 's estimated instantaneous default probability from $t-1$ to $t$ based on the assumption that the price of the firm's long bond at time $t$ is measured without error. If the model is specified correctly, there should be no persistent variations in the volatility of $\epsilon_{j, t}$, nor should its volatililty depend on $\hat{h}_{j, t-1}$ The regressions are estimated jointly across all 160 firms using quasi-maximum likelihood. $T$-statistics are in parentheses. 
Table 6

The relation between credit ratings and estimated default probabilities

Panel A. Parameter estimates grouped by firms' initial credit ratings ${ }^{a}$

\begin{tabular}{crrrrrrrr} 
Initial & \multirow{2}{*}{$\begin{array}{c}\text { Number } \\
\text { credit rating }\end{array}$} & \multicolumn{1}{c}{ Median Estimates } \\
\cline { 3 - 9 } & $\kappa_{j}$ & $\theta_{j}\left(\times 10^{2}\right)$ & $\lambda_{j}$ & $\sigma_{j}^{2}\left(\times 10^{2}\right)$ & $\kappa_{j} \theta_{j}\left(\times 10^{2}\right)$ & $\kappa_{j}+\lambda_{j}$ & $S_{j}^{2}\left(\times 10^{4}\right)$ \\
\hline Aaa & 5 & 0.000 & -0.361 & -0.182 & 1.275 & 0.018 & -0.118 & 0.776 \\
Aa & 35 & 0.000 & 0.000 & -0.066 & 0.369 & 0.000 & -0.060 & 0.288 \\
A & 80 & 0.000 & 0.000 & -0.109 & 0.473 & 0.000 & -0.080 & 0.565 \\
Baa & 38 & 0.000 & 0.000 & -0.096 & 0.405 & 0.000 & -0.060 & 0.571 \\
Ba & 2 & 0.063 & 2.049 & -0.385 & 1.753 & 0.074 & -0.321 & 3.204
\end{tabular}

Panel B. Estimated instantaneous default probabilities, sorted by contemporaneous credit rating

\begin{tabular}{crccc}
$\begin{array}{c}\text { Month } t \\
\text { credit rating }\end{array}$ & $\begin{array}{r}\text { Number of } \\
\text { observations }\end{array}$ & $\begin{array}{c}\text { Median } \hat{h}_{j, t} \\
\left(\times 10^{2}\right)\end{array}$ & $\begin{array}{c}\text { Mean } \hat{h}_{j, t} \\
\left(\times 10^{2}\right)\end{array}$ & $\begin{array}{c}{\left[\operatorname{Var}\left(\Delta \hat{h}_{j, t}\right)\right]^{1 / 2}} \\
\left(\times 10^{2}\right)\end{array}$ \\
\hline Aaa & 273 & 0.716 & 0.709 & 0.209 \\
Aa & 1421 & 1.011 & 1.036 & 0.233 \\
A & 5678 & 1.087 & 1.209 & 0.283 \\
Baa & 2678 & 1.659 & 2.095 & 0.896 \\
Ba & 251 & 2.589 & 2.781 & 0.655 \\
B & 21 & 4.187 & 5.496 & 3.459
\end{tabular}

Firm $j$ 's instantaneous probability of default $h_{j, t}$ is assumed to follow a square-root diffusion process with parameters $\kappa_{j}, \theta_{j}, \lambda_{j}$, and $\sigma_{j}^{2}$. In each month one bond price is assumed to be observed without error. All other log bond prices are observed with iid normally distributed measurement error with variance $S_{j}^{2}$. For each of 160 firms, this model is estimated with maximum likelihood, using one-month transition densities of log bond prices. The data set spans January 1985 through December 1994. Estimated values of $h_{j, t}$ are denoted $\hat{h}_{j, t}$.

a A firm's initial credit rating is defined as the credit rating on the firm's senior unsecured bonds in the first monthly observation used to estimate the firm's default process. 
Table 7

The relation between firms' estimated instantaneous default probabilities and their stock returns

$$
\begin{gathered}
100 \Delta \hat{h}_{j, t}=b_{0}+\sum_{i=0}^{3} b_{i+1} s_{j, t-i}+\eta_{j, t}, \\
E\left(\eta_{j, t}\right)=0, E\left(\eta_{j, t}^{2}\right)=V, E\left(\eta_{i, t} \eta_{j, t}\right)=\rho V, i \neq j, E\left(\eta_{i, t} \eta_{j, t-m}\right)=0, m \neq 0, \forall i, j .
\end{gathered}
$$

\begin{tabular}{|c|c|c|c|c|c|c|c|c|}
\hline \multirow{2}{*}{$\begin{array}{l}\text { Credit } \\
\text { rating }\end{array}$} & \multirow{2}{*}{$\begin{array}{c}\text { Num. of } \\
\text { Obs. }\end{array}$} & \multirow[b]{2}{*}{ Intercept } & \multicolumn{4}{|c|}{ _Stock Return } & \multirow[b]{2}{*}{$\rho$} & \multirow[b]{2}{*}{$V$} \\
\hline & & & Lag 0 & Lag 1 & Lag 2 & Lag 3 & & \\
\hline $\mathrm{Aa}$ & 832 & $\begin{array}{r}0.007 \\
(0.75)\end{array}$ & $\begin{array}{r}-0.298 \\
(-2.50)\end{array}$ & $\begin{array}{r}-0.106 \\
(-0.87)\end{array}$ & $\begin{array}{r}-0.110 \\
(-1.08)\end{array}$ & $\begin{array}{r}0.003 \\
(0.03)\end{array}$ & $\begin{array}{r}0.199 \\
(3.71)\end{array}$ & $\begin{array}{r}0.037 \\
(8.12)\end{array}$ \\
\hline $\mathrm{A}$ & 3996 & $\begin{array}{r}0.019 \\
(1.42)\end{array}$ & $\begin{array}{r}-0.409 \\
(-2.27)\end{array}$ & $\begin{array}{l}-0.386 \\
(-2.76)\end{array}$ & $\begin{array}{l}-0.059 \\
(-0.72)\end{array}$ & $\begin{array}{r}-0.091 \\
(-1.36)\end{array}$ & $\begin{array}{c}0.240 \\
(6.24)\end{array}$ & $\begin{array}{c}0.069 \\
(7.49)\end{array}$ \\
\hline Baa & 2086 & $\begin{array}{c}0.035 \\
(1.64)\end{array}$ & $\begin{array}{c}-1.374 \\
(-3.54)\end{array}$ & $\begin{array}{c}-0.356 \\
(-2.38)\end{array}$ & $\begin{array}{l}-0.357 \\
(-2.06)\end{array}$ & $\begin{array}{c}-0.763 \\
(-4.38)\end{array}$ & $\begin{array}{r}0.131 \\
(3.12)\end{array}$ & $\begin{array}{c}0.214 \\
(3.98)\end{array}$ \\
\hline
\end{tabular}

Firm $j$ 's estimated instantaneous probability of default at month-end $t$ is denoted $\hat{h}_{j, t}$. These estimates are produced assuming that a long-maturity bond price is measured without error. Firm $j$ 's stock return from the end of month $t-1$ to the end of month $t$ is denoted $s_{j, t}$. The regressions are estimated with quasi-maximum likelihood jointly across all $j, t$ with a given credit rating at $t-1$. $T$-statistics are in parentheses. 